\title{
Development and Validation of Multiplex One-Step Real-Time TaqManqRT-PCR Assays for Detection and Quantification of Arboviral Encephalitis Viruses
}

\author{
Donggen Zhou*, Jie Luo \\ Ningbo International Travel Healthcare Center, Ningbo, China \\ Email: *dongdong1004@163.com
}

How to cite this paper: Zhou, D.G. and Luo, J. (2018) Development and Validation of Multiplex One-Step Real-Time TaqManqRT-PCR Assays for Detection and Quantification of Arboviral Encephalitis Viruses. Advances in Microbiology, 8, 519-557. https://doi.org/10.4236/aim.2018.87036

Received: June 26, 2018

Accepted: July 24, 2018

Published: July 27, 2018

Copyright $\odot 2018$ by authors and Scientific Research Publishing Inc. This work is licensed under the Creative Commons Attribution International License (CC BY 4.0).

http://creativecommons.org/licenses/by/4.0/

\begin{abstract}
Arboviral encephalitis is a group of animal and human illness that is mostly caused by several distinct families of viruses including orthobunya virus, phlebovirus, flaviviruses, and the alphaviruses. Although specific signs and symptoms vary by the type of central nervous system (CNS), initial signs and symptoms are very similar. Therefore rapid immunologic and molecular tools for differential diagnosis of arboviral encephalitis viruses are important for effective case management and control of the spread of encephalitis. The qRT-PCR assay, especially multiplex PCR, has the potential to produce considerable savings in time and resources in the laboratory detection. Meanwhile, the use of IC can prevent false negatives effectively by monitoring the processes of nucleic acid extraction and amplification. This report describes the development of a panel of internally controlled multiplex one-step real-time RT-PCR assays in which two virus specific-probe sets were used in the same reaction for the detection of 15 species arboviral encephalitis viruses: the comparative sensitivity of multiplex one-step qRT-PCR assays to single plex one-step qRT-PCR assays as well as one-step RT-PCR assays for detection of each viral species. And total of 150 human serum samples were detected to evaluate the multiplex one-step qRT-PCR assays. These multiplex one-step real-time RT-PCR assays with IC were evaluated in terms of sensitivity, linearity, precision, specificity, and also field samples including serum and vector. These assays can detect and differentiate arboviral encephalitis viruses by high throughput, sensitive, and specific way. It is useful for clinical management and outbreak control of arboviral encephalitis viruses and vector surveillance.
\end{abstract}




\section{Keywords}

Multiplex One-Step Real-Time TaqManqRT-PCR Assays, Arboviral

Encephalitis Viruses, Internal Control

\section{Introduction}

Arboviral encephalitis is caused by infection with an arbovirus, which transmitted by a mosquito, tick or another arthropod. The commonest cause of human disease is flaviviruses, alphaviruses, orthobunyavirus and the phlebovirus [1] [2] [3]. Eastern equine Encephalitis virus (EEEV) [4] [5], Western Equine Encephalitis virus (WEEV) [6] [7] and Venezuelan Encephalitis virus (VEEV) [8] belong to the alphaviruses, Japanese Encephalitis virus (JEV) [9], St. Louis Encephalitis virus (SLEV) [6] [10] [11], West Nile virus (WNV) [5] [6] [12] and Tick-borne Encephalitis virus (TBEV) [13] [14] [15] [16] are from the flaviviruses, while California Encephalitis virus (CEV) and La Crosse virus (LACV) [17] are members of the orthobunyavirus, and Rift Valley Fever virus (RVFV) [18] [19] and Toscana virus (TOSV) [20] are members of the phlebovirus. Many types of arboviral encephalitis occur throughout the world. They include Japanese Encephalitis (JE), Rift Valley Fever (RVF), Tick-borne Encephalitis (TBE), Murray Valley Encephalitis (MVE) [21] [22] and, most notorious of all, the West Nile virus (WNV) [23] [24] which causes West Nile encephalitis, also known as West Nile fever.

Recently, increasing evidence has shown that certain arboviruses such as dengue virus and chikungunya virus may occasionally cause encephalitis in addition to their conventional symptoms, which usually involves headaches, muscle and joint pain, and rashes [25] [26] [27] [28]. Most of these diseases are problems only for those individuals traveling to countries where the viruses are endemic, having similar symptoms. Therefore, it is too difficult to distinguish the various etiologic agents based on clinical signs and symptoms, which makes the accurate and timely laboratory detection of viruses important in early diagnosis of arboviral encephalitis.

In view of its identifying the selected target gene of RNA viruses rapidly and specifically, probe-based real-time quantitative reverse transcription-polymerase chain reaction (qRT-PCR) assay is widely used for virus detection. Some methods for detection of arboviral encephalitis viruses have been published, which provides useful references for people working on them. However, most of these qRT-PCR assays may cover only one or parts of virus strains.

Meanwhile, despite the large number of reported arboviral encephalitis virus real-time RT-PCR assays, few of these assays have been designed to include an internal control (IC), either as an extrinsic molecule spiked into each sample before or after extraction or as a heterologous intrinsic target that is co-extracted with viral RNA. It has been advocated that ICs be used in settings where PCR 
inhibitors present a significant source of false-negative results, which may be particularly important in the performance of nucleic acid detection [29].

Therefore, a panel of reliable comprehensive duplex one-step real-time qRT-PCR assays covering all important pathogens, suitable for multiplex screening or specific quantitative identification with fast turn-around time and identical cycling parameters is still urgently needed, so that the unknown samples can be tested simultaneously and effectively.

Here, we established a panel of species-specific internally controlled one-step real-time qRT-PCR assays for multiplex detection of 15 viruses, which covered nearly all the important viral pathogens that cause arboviral encephalitis, including Eastern equine encephalitis virus (EEEV), Western Equine Encephalitis virus (WEEV), Venequilan Equine Encephalitis virus (VEEV), Japanese Encephalitis virus (JEV), Saint Louis Encephalitis virus (SLEV), Murray Valley Encephalitis virus (MVEV), West Nile virus (WNV), Powassan virus (POWV), California Encephalitis virus (CEV), La Crosse virus (LCV), Tick-borne Encephalitis virus (TBEV), Rift Valley Fever virus (RVFV), Toscana virus (TOSV), Dengue virus (DENV), Chikungunya virus (CHIKV) and internal control (IC). All assays were optimized at a same thermal cycling condition, and evaluated under single plex, duplex qRT-PCR assays or RT-PCR assays for detection of the in vitro-transcribed Viral RNAs, which were proved to be reliable molecular tools of early diagnosis. And total of 150 RNA samples from human serum were examined using the multiplex one-step real-time qRT-PCR assays. The duplex one-step real-time qRT-PCR assays were verified that the assays were sensitive, specific and reliable methods for detection of arboviral encephalitisis viruses. And they are useful for clinical management and outbreak control of arboviral encephalitisis viruses and vector surveillance.

\section{Materials and Methods}

\subsection{Primers and Probes Design}

In this study, 15 species viruses were detected, all of genomic sequences were all retrieved from the GenBank database of NCBI

(http://www.ncbi.nlm.nih.gov/nuccore/). The multiple alignments and identification of conserved regions of genomic sequences were carried out respectively by Perl script, which using Clustal W alignment program and sequence analysis algorithm. Primers and probe for each virus were designed using a Primer Premier software (version 3.0), and optimized using Oligo software (version 6.0) by analysis of potentials for dimerization, cross-linking and secondary structures. The specificity of primer and probe sequences was further confirmed using primer-BLAST (NCBI). The probes were differently labeled with the fluorescent dyes, FAM, HEX. All oligonucleotides were synthesized by Invitrogen Technology Co., Ltd.

\subsection{IC Design}

The IC nucleic acids contained primer-binding regions that were designed ac- 
cording to the sequence of the tobacco mosaic virus (isolate Guangyuan, complete genome, http://www.ncbi.nlm.nih.gov/nuccore/HE818460.1). The details of its primers and probes are listed in Table 1 . In order to check from RNA extraction to amplification, IC DNA sequence was inserted into pET28a (+) - MS2 vector and then be constructed to an IC sequence RNA contained armored virus.

\subsection{Viruses and Sample Preparation}

Viral isolates propagated in $\mathrm{C} 6 / 36$ or Vero cells, including DENV 1-4 types,

Table 1. Primers, probes, and amplicon sizes of the one-step real-time qRT-PCR assays.

\begin{tabular}{|c|c|c|c|c|c|c|}
\hline Group & Viruses & $\begin{array}{c}\text { GenBank } \backslash \text { Accession } \\
\text { No. }\end{array}$ & $\begin{array}{c}\text { Forward } \\
\text { Primers/Tm value }\end{array}$ & Reverse Primers/Tm value & Probes/Tm value & $\begin{array}{l}\text { Ampliconsize } \\
\text { (bp) }\end{array}$ \\
\hline \multirow{4}{*}{ A } & EEEV & NC_003899.1 & CTGTGTGTTCGTACGCTG & GCTGCTTATTTTGCTGTGG & CGCCCAAGGCGCCG & 75 \\
\hline & & & CG/60.1 & GC/60/7 & CAGACAA/74.7 & \\
\hline & WEEV & NC_003908.1 & GATCGGGCCGTCCATGAG & GCTTCTATTTCCTTCAGAG & TACGCCCCGCGCCTC & 105 \\
\hline & VILL & 120 & $/ 61$ & GCG/58.3 & GATC/69.3 & 105 \\
\hline \multirow{4}{*}{ B } & VEEV & NC 0014491 & CCCCGTTCAATGTGTCTG & CAGGCTATGCTGCTACGAT & ГTTGCAGCACAAGAAT & 69 \\
\hline & & 1 & TCAC/61.2 & GC/59.6 & CCCTCGCG/69.1 & \\
\hline & CHIKV & NC_004162.2 & TGGCTTTTTTAGCCGTAA & CGGTACTCCCACCGTGTTC' & TCGGTGCCCACACTG & 88 \\
\hline & & & 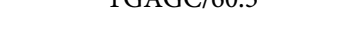 & $\mathrm{G} / 02.2$ & IGAGCGC/71.5 & \\
\hline \multirow{3}{*}{$\mathrm{C}$} & MVEV & NC_000943.1 & GCCATGATGGTGATGCAA & CTGTCTGGGAATGAGCAG & TCGCCCTCCAGCACC & 99 \\
\hline & & & & & & \\
\hline & SLEV & NC_007580.2 & $\begin{array}{l}\text { CTTGTGCGTCCTCTCCAG } \\
\text { CC/61.8 }\end{array}$ & $\begin{array}{c}\text { CTGGGTGCAAAGCCCCTC/ } \\
60.2\end{array}$ & $\begin{array}{l}\text { CGTGCCAGGGACCCT } \\
\text { CCCGAGTC/72.4 }\end{array}$ & 68 \\
\hline \multirow{4}{*}{$\mathrm{D}$} & WNV & NC 001563.2 & CAGCGATCTCTCCACCAA & GGGTCAGCACGTTTGTCAT" & rTGCCCGACCATGGGA & 69 \\
\hline & & & AGC/60.8 & TG/60 & GAAGCTCA/70.6 & 69 \\
\hline & JEV & NC_001437.1 & ACTGGGTTACCAAAGCCG & AGTCCTTCCACСТССТСТА & CCCCCACGGCCCAAG & 152 \\
\hline & & & TTG/59.9 & CAGC/58.9 & CCTCGT/73.5 & \\
\hline \multirow{5}{*}{$\mathrm{E}$} & CEV & U12800.1 & AGCAGGATATAGGTCATT & GCCAATCGCAGTTGCTTAT & CCCCAGGTGTGCCAC & 90 \\
\hline & $\mathrm{CEV}$ & 012000.1 & TCTGCC/58.7 & ATG/58.4 & TGTTAGATTCC/68.1 & 90 \\
\hline & \multicolumn{5}{|c|}{ CATTTGCAAGAGAGAGGA } & \\
\hline & LCV & NC 0041091 & ATACACACCCATCACTTA & CAAGC/ & AGGCAACCAAACTCT & \\
\hline & $\operatorname{LCV}$ & NC_004109.1 & CAGCC/56.7 & $\begin{array}{c}\text { CATTTGCAAGAGAGAGGA } \\
\text { CAAGT } / 59.1\end{array}$ & TCGCATCCCC/69.5 & 75 \\
\hline \multirow{4}{*}{$\mathrm{F}$} & POWV & NC_003687.1 & $\begin{array}{l}\text { GGCACTCСССАACTCCG/ } \\
\text { GGCACTCCСCAGCTCCA/5 }\end{array}$ & GCTGGGGCAAGTCAATCTT & Г TCAАСССССАТСАТС & 81 \\
\hline & & & 9.3 & $\mathrm{G} / 59.4$ & ATC & \\
\hline & TBEV & NC 001672.1 & GGGGGGCGGTTCTTGTT/5 & CACACATCACCTCCTTGTC & CTCCCTGAGCCACCA & 72 \\
\hline & & & 9.3 & AGAC/58.2 & TCACCCAGAC/69.6 & $1 / 2$ \\
\hline \multirow{4}{*}{ G } & TOSV & NC 006320.1 & CTAACTGGGCCACACACA & TCACCATTGCTCGCACTGG & CTGCCTATTCCCCCC & 135 \\
\hline & & & TGC/60 & $/ 60.4$ & CTAACCCC/67 & \\
\hline & RVFV & NC_014396.1 & CTTGACCCCCTTCAACAT & CTCCAGAATCACCACTTGC & AAGCCTCTGCCCCAA & 121 \\
\hline & & & CAAA $/ 59.8$ & TCTAC/58.1 & CTGACCCTGC/71.6 & \\
\hline \multirow[t]{4}{*}{$\mathrm{H}$} & DENV & NC 001474.1 & CAAAAGGAAGTCGYGCA & CTGAGTGAATTCTCTCTGC & CATGTGGYTGGGAGC & 112 \\
\hline & & & ATA/53.8 & TRAAC/ 56.5 & RCGC/65.5 & \\
\hline & IC & HM745932 & GTCAAGATCCTCAAAGAT & ACTCTTGGCCGTTGGTTTG & AGTTTGGAGTCTTGG & 113 \\
\hline & & 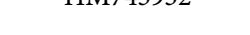 & ACAGCT/54.8 & /57.3 & ATGTCGCAT/62 & \\
\hline
\end{tabular}


CHIKV, TBEV, RVFV and WNV were provided by Wuhan institute of virology, CAS. Human serum samples from healthy persons $(n=150)$ were assembled from samples library of Ningbo International travel healthcare center. The human serum from JEV patients $(\mathrm{N}=20)$, TBEV patients $(\mathrm{N}=13)$ and DENV patients $(\mathrm{N}=29)$ in the acute phase were from Ningbo center for disease prevention and control, other serum from DENV patients $(\mathrm{N}=16)$ and CHIKV patients $(\mathrm{N}=8)$ were from laboratory of Ningbo International travel healthcare center, which were all confirmed by single plex real-time qRT-PCR assays, and other specific detection methods (virus isolation or IgG detection). These healthy human serums were used as negative control in all the tests, whereas the other viral isolates were implied as positive control in the detection assays for different viruses. Vector tissue samples were collected by our laboratory during vector surveillance in 2015 , including mosquito pools $(\mathrm{N}=112)$ and tick $(\mathrm{N}=$ $38)$.

\subsection{RNA Extraction}

RNA samples used for detection and quantification were prepared using QIAampViral RNA Mini Kit (Qiagen). A total 140 ul of samples which from serum,strain and culture supernatant of virus-infected cells were used for detection and quantification. RNA extraction was performed according to the manufacturer's instructions for use of the RNA extraction procedure selected, and finally eluted in $60 \mu \mathrm{L}$ sterilized RNase free water. Viral RNA samples were stored at $-80^{\circ} \mathrm{C}$ before use, and samples are aliquoted into sample sizes adequate for future use in the lab in order to avoid repeated freeze-thawing.

\subsection{Preparation of Viral RNA Standards in Vitro Transcription}

Single-stranded DNA fragments containing cDNA derived from (DENV, CHIKV, TBEV, RVFV and WNV) which obtained through chemical synthesis or RT-PCR amplification from viral isolates, andcontaining a 5'T7 RNA polymerase promotersequence (TAATACGACTCACTATAGGG) were synthesized. Single-stranded DNA fragments were purified using the Gel Extraction Kit (Qiagen) and performed according to the protocal. Subsequently, the purified single-stranded DNA fragments were transcribed by T7 RNA polymerase using RiboMAXTM Large Scale RNA Production Systems-T7 (Promega), and Viral RNA standards prepared according to the manufacturer's instructions for use. After in vitro transcription, the RNA transcripts were purified by RNeasyMini Kit (Qiagen), the concentration of RNA transcripts was measured using a NanoDrop ND-1000 spectrophotometer (NanoDrop Technologies), and evaluated by $2 \%$ agarose gel electrophoresis in the presence of ethidium bromide and visualized by fluorescence under UV light. Dilutions of viral RNA standards ranging from $1.0 \times 10^{3}$ to $1.0 \times 10^{7}$ copies $/ \mu \mathrm{L}$ were prepared by 10 -fold serial dilution of RNA transcripts in sterilized RNase free water according to the concentration and length of each transcript. 


\subsection{Development of Multiplex One-Step Real-Time qRT-PCR Assays}

To reduce the assay cost and improve condition for the multiple reaction. Multiplex assays were assembled by grouping the primers and probes according to the hosts/Vectors or viral families for the duplex reaction. Originally, the linear dynamic range of detection for reaction containing one primer-probe set (singleplx) and multiple prime-probe sets for multiple targets (duplex) was determined using One-step real-time qRT-PCR in duplicates with 10-fold serial dilution of a single species of target RNA. Singlex or Multiplex One-step real-time qRT-PCR reactions were performed using AgPath-ID ${ }^{\mathrm{TM}}$ one-step RT-PCR Kit (Applied Bio systems), and performed according to the protocol. It was performed in a total reaction volume of $25 \mathrm{ul}$ consisting of $12.5 \mu \mathrm{L}$ of $2 \times \mathrm{RT}$-PCR buffer, $400 \mathrm{nM}$ of each primer, $120 \mathrm{nM}$ of each probe, $1 \mu \mathrm{L}$ of Enzyme Mix and 5 $\mu \mathrm{L}$ of viral RNA transcripts or RNA samples. DEPC water was used as negative control. The qRT-PCR standard curve ranging from $1.0 \times 10^{3}$ to $1.0 \times 10^{7}$ copies $/ \mu \mathrm{L}$, was generated from a 10 -fold serial dilution of RNA transcripts. Real-time qRT-PCR cycling was performed on ABI 7500 fast system as follows: $45^{\circ} \mathrm{C}$ for 10 $\mathrm{min}, 95^{\circ} \mathrm{C}$ for $15 \mathrm{~min}$, then 40 cycles of $15 \mathrm{~s}$ at $95^{\circ} \mathrm{C}$ for denaturation and $60 \mathrm{~s}$ at $60^{\circ} \mathrm{C}$ for annealing and extension incubations. Raw data was analyzed with 7500 Software v2.0.6 to determine the amount of viral RNA base on the threshold cycle value $(\mathrm{Ct})$. Multiplex one-step real-time $\mathrm{qRT}$-PCR assays and single one-step real-time qRT-PCR assays were compared for each of the species viruses.

\subsection{One-Step RT-PCR Assays}

As the standard for comparison, One-step RT-PCR arrays were conduct according to previously reported method. One-step RT-PCR reactions were performed using Ag Path-ID ${ }^{\mathrm{TM}}$ one-step RT-PCR Kit (Applied Bio systems), and performed according to the protocol. Briefly, the primers for RT-PCR of each assay are the same as those for qRT-PCR. Also, the templates for RT-PCR are the same as those for qRT-PCR, including the reaction system. The amplified product was analyzed by electrophoresis using $2 \%$ agarose gel. The gel was stained with ethidium bromide and the amplified product was visualized under UV light. Multiplex One-step real-time qRT-PCR assays and One-step RT-PCR assays were compared for sensitivity for 15 species viruses.

\subsection{Specificity, Sensitivity and Reproducibility}

To assess the specificities of the developed multiplex one-step real-time qRT-PCR assays, each pair of primer-probe was tested in duplicates against all the other in vitro synthetic viral RNA transcripts with the concentration of $1.0 \times$ $10^{6}$ copies/ $\mu \mathrm{L}$, RNA samples of DENV, CHIKV, TBEV, RVFV, WNV, WEEV and EEEV, as well as serum RNA were extracted from a panel of 150 sera from human without CNS. 
To evaluate sensitivity of single plex, multiplex one-step real-time qRT-PCR assays, single plex one-step real-time qRT-PCR assays and one-step RT-PCR assays, each group of 10-fold serial dilutions of RNA transcripts, ranging from 1.0 $\times 10^{3}$ to $1.0 \times 10^{7}$ copies $/ \mu \mathrm{L}$, were used as standard preparations to assess the detection limits of viral RNA copy load. Duplicates of the assay within or between runs were performed to assess the reproducibility, and the intra-assay and inter-assay variations over the linear range of the assays were statistically calculated.

\subsection{Statistical Analysis}

Regression, reproducibility and the coefficient of variation (CV)of the mean Ct value for each standard concentration within and between individual PCR runs were statically calculated by SPSS 15 to evaluate linearity and determine the quantitative performance of each assay.

Calculation method: $C t$ (threshold cycle) is the intersection between an amplification curve and a threshold line. It is a relative measure of the concentration of target in the PCR reaction.

Equation for $C t$ value: $\lg X 0=-C t \times \lg (1+E x)+\lg M$

Linear equation:

$$
\text { Efficiency }=\left(10^{\frac{-1}{\text { slope }}}-1\right) \times 100 \%
$$

\section{Result}

\subsection{Primer-Probe Selection and Design}

Genomic sequences of all representative strains of each viral species were downloaded from the GenBank database (Supplementary Table S1). The internal control (IC) chooses synthetic construct sequence as the target gene having no homology with these arboviral encephalitis viruses. In total, 16 primer-probe pairs were designed. All primers-probes were grouped into eight groups for the duplex reaction based on the related diseases or virus families. Using the developed reaction system, we tested each primer/probe set in the single plex assays, and then combined them into duplex reactions for multiplex one-step real-time qRT-PCR assays according to Table 1 .

\subsection{Generation of Viral RNAs}

For further assessment of specificity and sensitivity for the developed Multiplexone-step real-time qRT-PCR assays, one-step real-time qRT-PCR assays, and one-step RT-PCR assays against the Viral RNAs as the closets virus with DENV, CHIKV, TBEV, RVFV and WNV, Viral RNAs were used and generated via in vitro transcription of single-stranded DNA fragments containing cDNA derived from (DENV, CHIKV, TBEV, RVFV and WNV) and T7 RNA polymerase promoter sequence. The $260 \mathrm{~nm} / 280 \mathrm{~nm}$ ratios were all between 2.0 and 2.1, 
indicating that the RNA products were highly pure. The concentration of RNA transcripts was quantified and the copynumbers were calculated respectively according to the concentration and size of each single-stranded RNA fragment (Supplementary Table S2). The invitro-transcribed Viral RNAs were used in the Multiplexone-step real-time qRT-PCR assays, one-step real-time qRT-PCR assays, and one-step RT-PCR assays for specificity and sensitivity evaluation.

\subsection{Sensitivity and Reproducibility of Multiplex One-Step qRT-PCR Assays}

The sensitivity of multiplex one-step qRT-PCR assays, single plex one-step qRT-PCR assays and one-step RT-PCR assays for detection of each viral species. As shown in Supplementary Table S2, The in vitro-transcribed Viral RNAs were subjected to the sensitivity test. The RNA transcripts as RNA standards were serially diluted 10 -folds from $1.0 \times 10^{3}$ to $1.0 \times 10^{7}$ copies $/ \mu \mathrm{L}$. Sensitivity of multiplex one-step qRT-PCR assays, single plex one-step qRT-PCR assays and one-step RT-PCR assays was amplified as RNA samples. The amplification efficiencies of the single plex assays for the 15 arboviral encephalitis viruses were all above $90 \%$. The standard curves showed a high correlation coefficient, $\mathrm{R}^{2}>0.99$, for all the viruses detections (data not shown). The potential limits of detection (LODs) of these assays were determined to be at a range from 85.7 to 155.7 RNA copies/PCR (Table 2). The synthesized RNA standards were used for the multiplex assays testing, and standard curves of detections for each virus RNA transcripts were also constructed and showed high correlation coefficient, $\mathrm{R}^{2}>0.98$ (Figure 1). In most multiplex assays (13 out of 15 virus detections), the LODs were at a range from 94 to 150 RNA copies/PCR, which was similar to that in the single plex assays (Table 2). Besides, WEEV and JEV detection assays showed a little lower sensitivity with the LODs of 215.6 and 174.3 copies/PCR, respectively. As shown in Table 2, duplex qRT-PCR was 1000-fold more sensitive than one-step RT-PCR for the amplification of EEEV, WEEV, VEEV, RVFV, JEV and TOSV, and was 100-fold more sensitive than one-step RT-PCR for that of WNV, CEV, LCV, POWV, TBEV and DENV, and was 10-fold more sensitive than one-step RT-PCR for that of MVEV and CHIKV (Figure 1). The analysis of the LOD indicated that the strategy of multiplex detection ensures the sensitivity of the assay system.

The reproducibility of the multiplex one-step real-time QRT-PCR assays for detection of each viral species, duplicates of the assay within or between runs were performed. And mean CT values were calculated at a serial dilution of viral RNA transcript standards (from $1.0 \times 10^{3}$ to $1.0 \times 10^{7}$ copies $/ \mu \mathrm{L}$ ), and the variations within and between runs in the linear range of the assays were statistically analyzed (Supplementary Table S3). The coefficients of variation (CVs) of CT values were all less than $5 \%$ with $0.06 \%-4.95 \%$ for intra-assays and $0.09 \%$ $4.98 \%$ for inter-assays (Figure 2), suggesting that the developed multiplex one-step real-time qRT-PCR assay is reproducible. 
Table 2. Detection limits of multiplex one-step real time qRT-PCR assays.

\begin{tabular}{|c|c|c|c|c|}
\hline \multirow[b]{2}{*}{ Group } & \multirow{2}{*}{$\begin{array}{l}\text { Detected } \\
\text { viruses }\end{array}$} & \multicolumn{3}{|c|}{ Limits of detection (copies/UL) } \\
\hline & & $\begin{array}{c}\text { Single plex qRT-PCR } \\
\text { assays }\end{array}$ & $\begin{array}{l}\text { Duplexq RT-PCR } \\
\text { assays }\end{array}$ & RT-PCR assays \\
\hline \multirow{2}{*}{ A } & EEEV & 133.5 & 114.4 & 114,400 \\
\hline & WEEV & 155.7 & 215.6 & 215,600 \\
\hline \multirow{2}{*}{ B } & VEEV & 94.3 & 134.8 & 134,800 \\
\hline & CHIKV & 103.5 & 146 & 146 \\
\hline \multirow{2}{*}{$\mathrm{C}$} & MVEV & 114.2 & 124.8 & 124,800 \\
\hline & SLEV & 116.9 & 110.4 & 1104 \\
\hline \multirow{2}{*}{$\mathrm{D}$} & WNV & 105.6 & 116.5 & 11,650 \\
\hline & JEV & 100.1 & 174.3 & 174,300 \\
\hline \multirow{2}{*}{ E } & CEV & 143.9 & 143.5 & 14,350 \\
\hline & LCV & 85.7 & 94.1 & 9410 \\
\hline \multirow{2}{*}{$\mathrm{F}$} & POWV & 86.3 & 124.3 & 12,430 \\
\hline & TBEV & 90.4 & 103.5 & 10,350 \\
\hline \multirow{2}{*}{ G } & TOSV & 78.1 & 107.1 & 10,710 \\
\hline & RVFV & 101.3 & 110.6 & 1106 \\
\hline $\mathrm{H}$ & DENV & 110.8 & 131.2 & 131,200 \\
\hline
\end{tabular}

\subsection{Application of Multiplex One-Step qRT-PCR Assays}

To verify that multiplex one-step qRT-PCR assays was detecting infectious virus and not simply RNA, the cross-reactivity of the single plex primers/probe was examined using all the in vitro transcribed viral RNA standards with the concentration of $10^{6}$ copies/ $\mu \mathrm{L}$. We also attempted to 150 RNA samples in the test. RNA samples were isolated Viral RNAs from clinical specimens, healthy human sera and sera from the respective patients infected with individual viruses and vectors infected with individual virus. According to the criteria of qualitative determination in this study, the detection results of all the samples were determined. The multiplex one-step real-time qRT-PCR assays on four related groups of duplex qRT-PCR assays, including Group B, Group D, Group F and Group H, were performed for test the diagnostic specificity and sensitivity in comparison with signleplex qRT-PCR assays. The result showed that no cross-amplification reaction for any other virus was observed in GRT-PCR assays. And all of the specific reactions had high positive fluorescence signals, and mean CTs were in the range of 17 - 24 (Table 3). In addition, there was also no significant nonspecific amplification plots obtained in the testing of RNA samples which isolated from human serum (Table 4). The 15 species viruses qRT-PCR assays were suggested to be $100 \%$ at a cut-off $\mathrm{Ct}$ value. It was indicated that the specificity of the developed one-step real-time qRT-PCR assay is considered satisfactory, and the primers/probe sets will be applicable for the multiplex assays. 

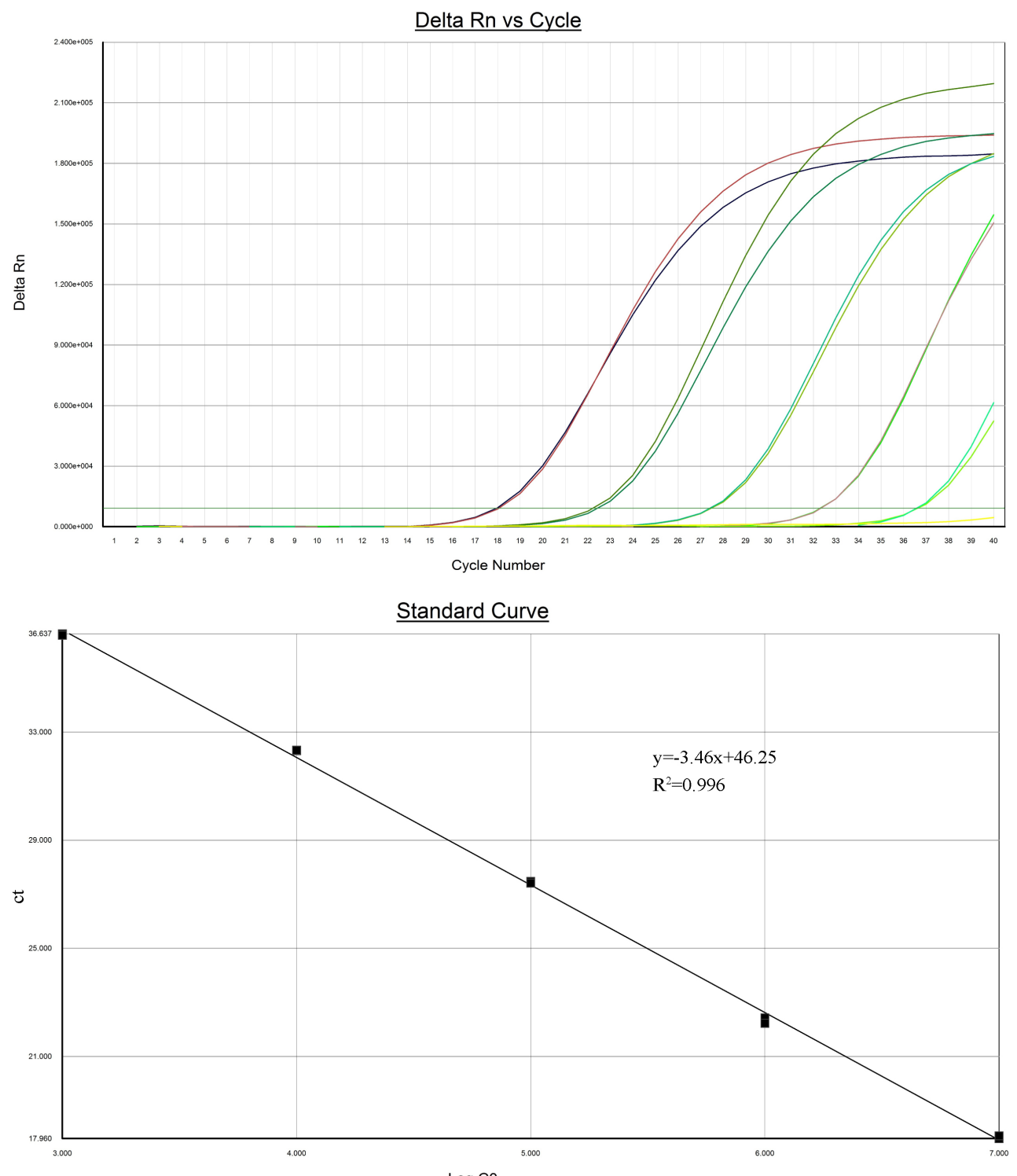

$\log \mathrm{CO}$

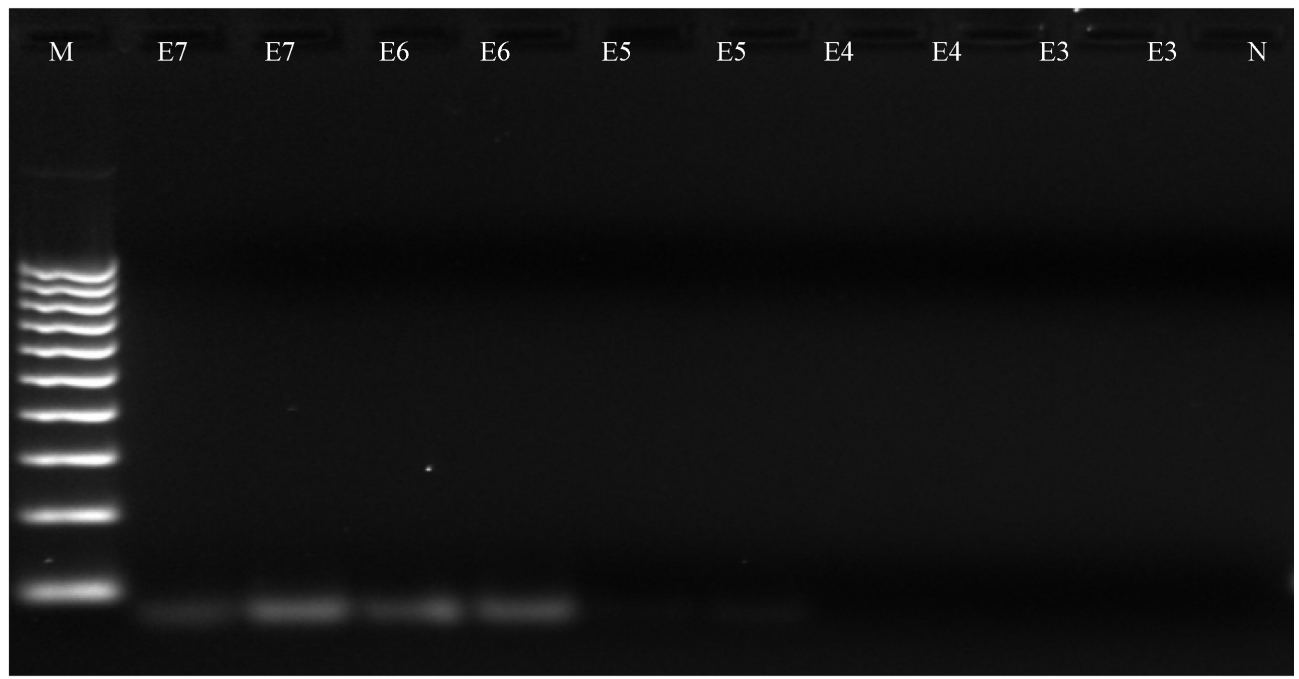

(a) 


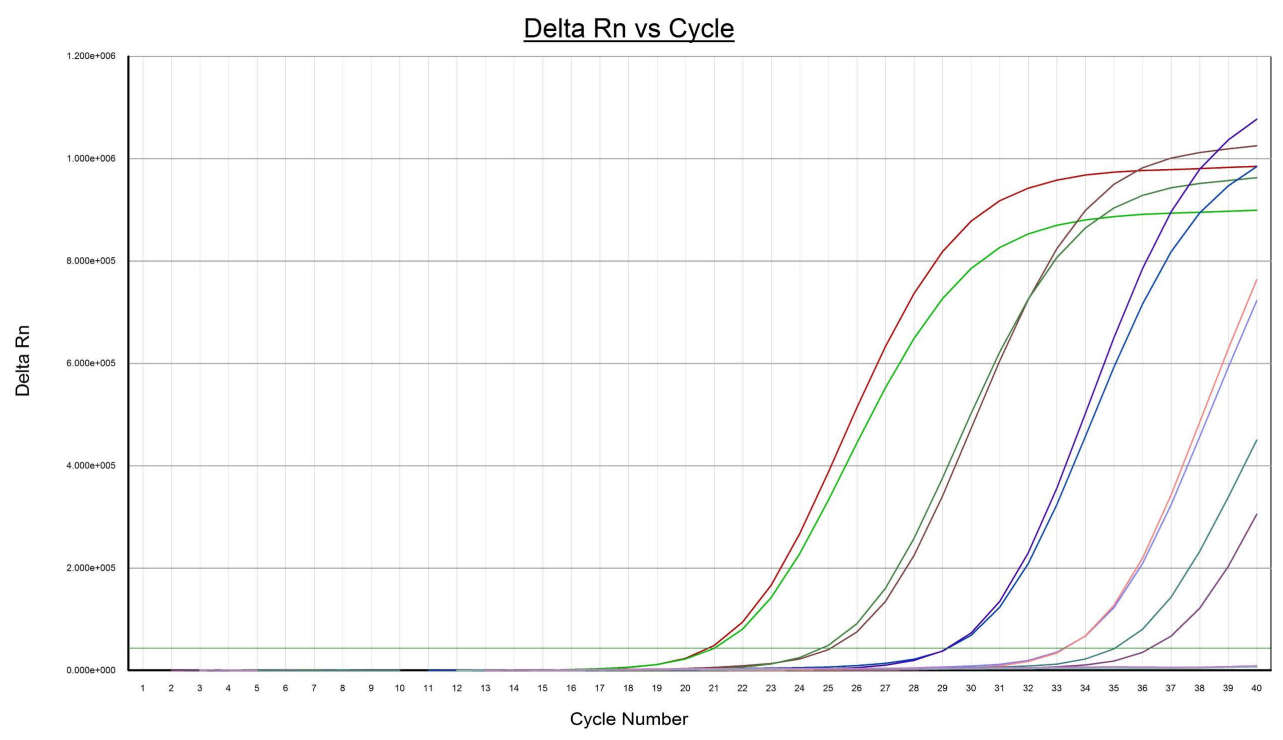

$\underline{\text { Standard Curve }}$
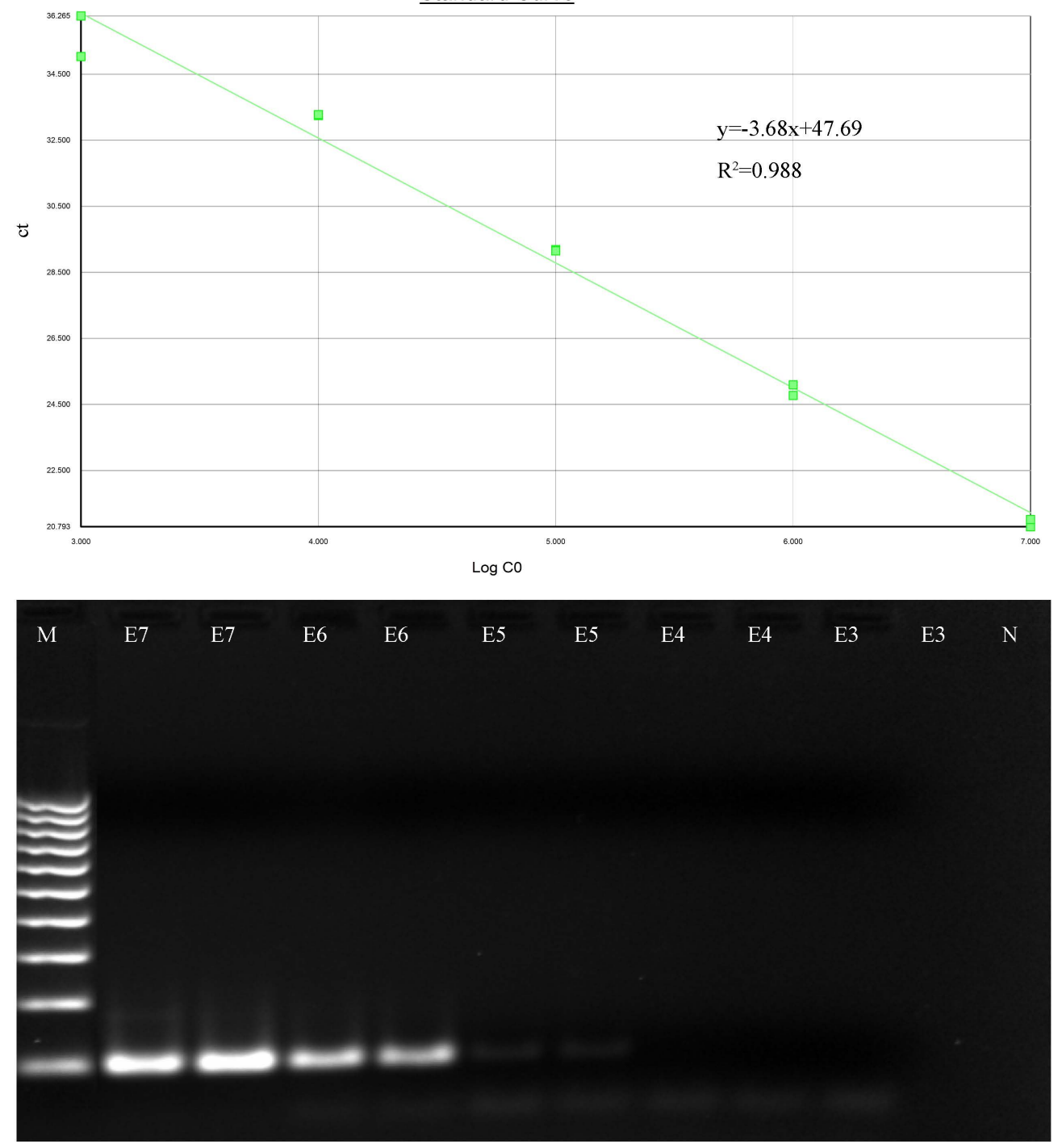

(b) 

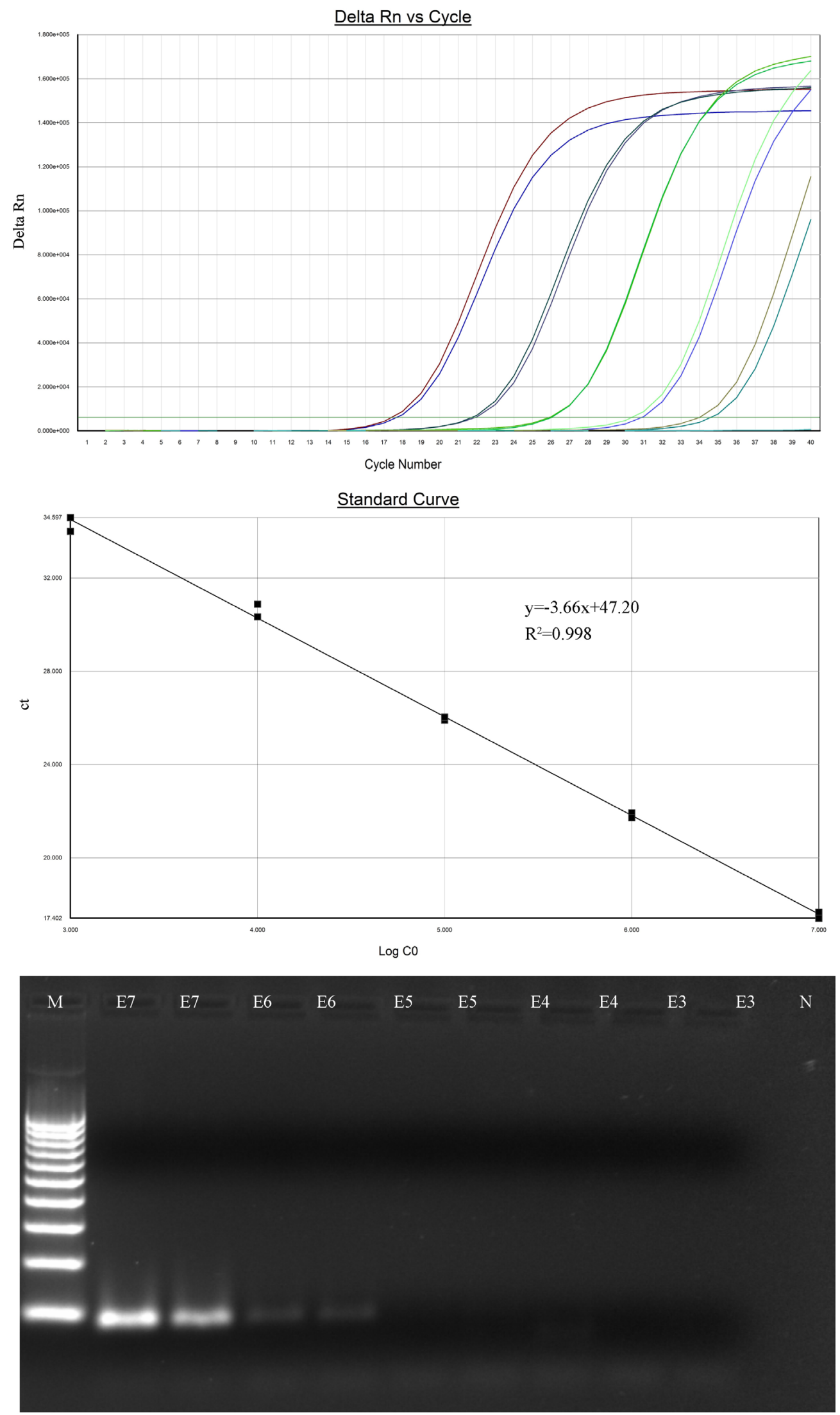

(c) 

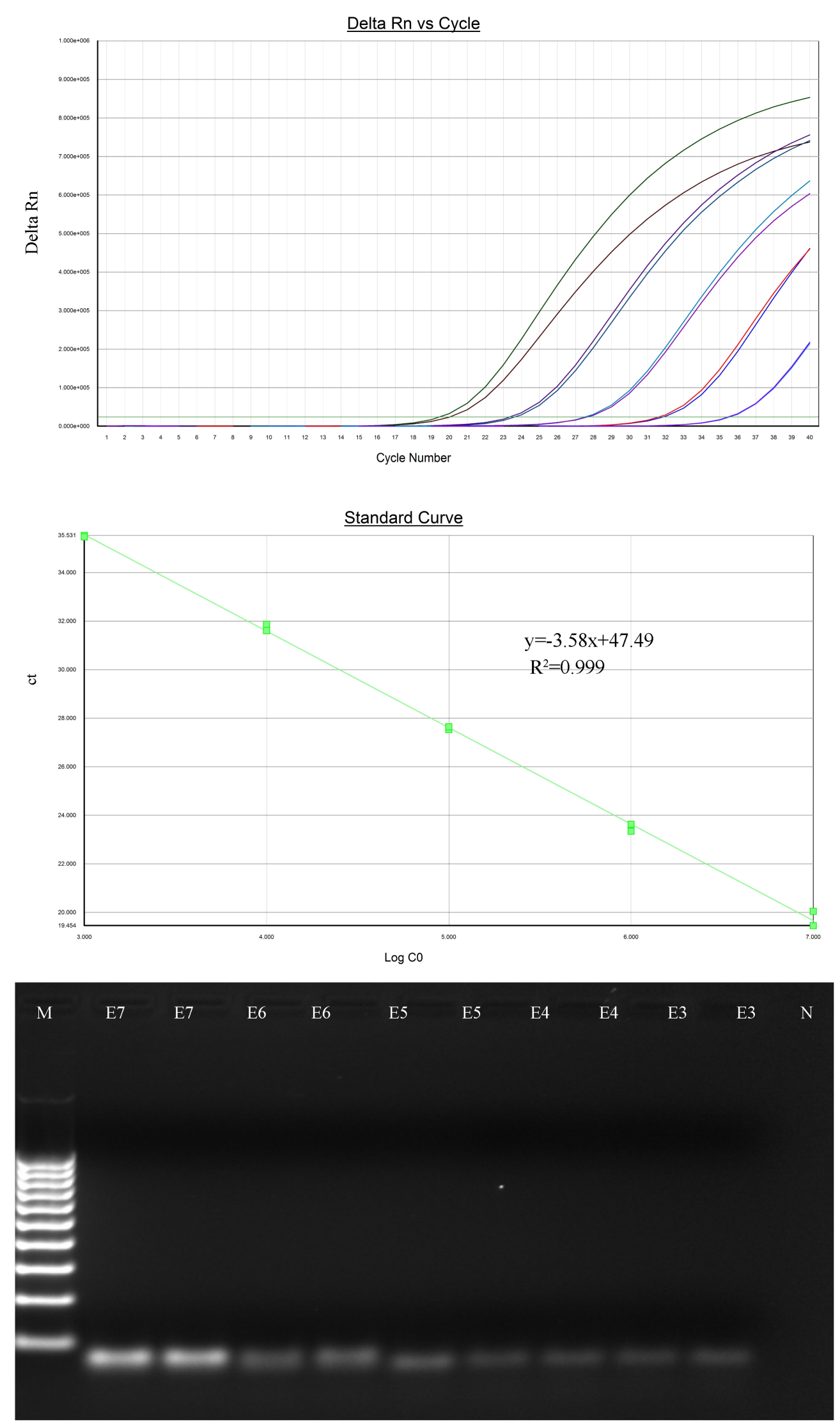

(d) 

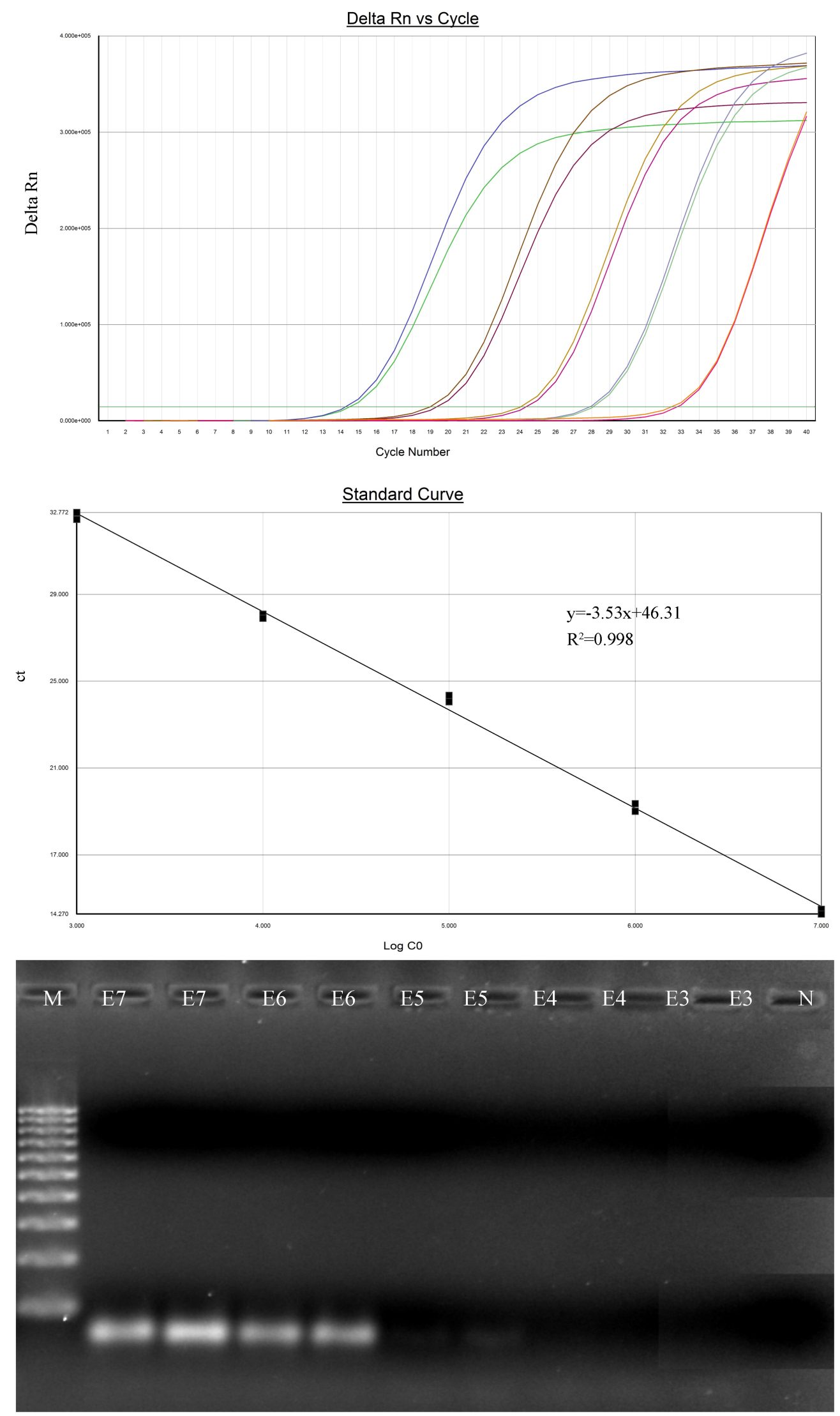

(e) 

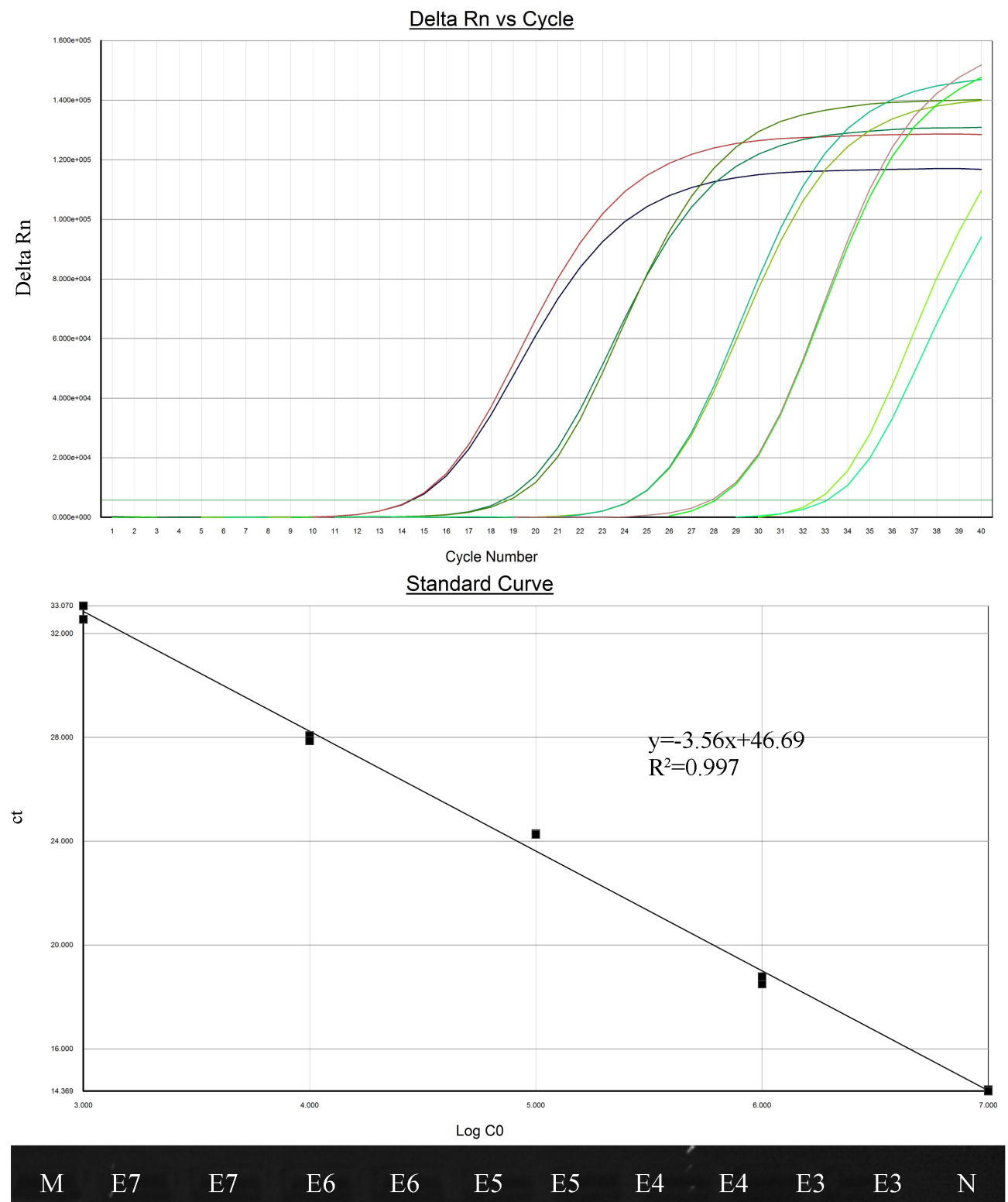

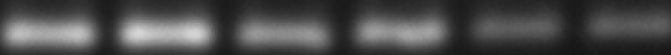



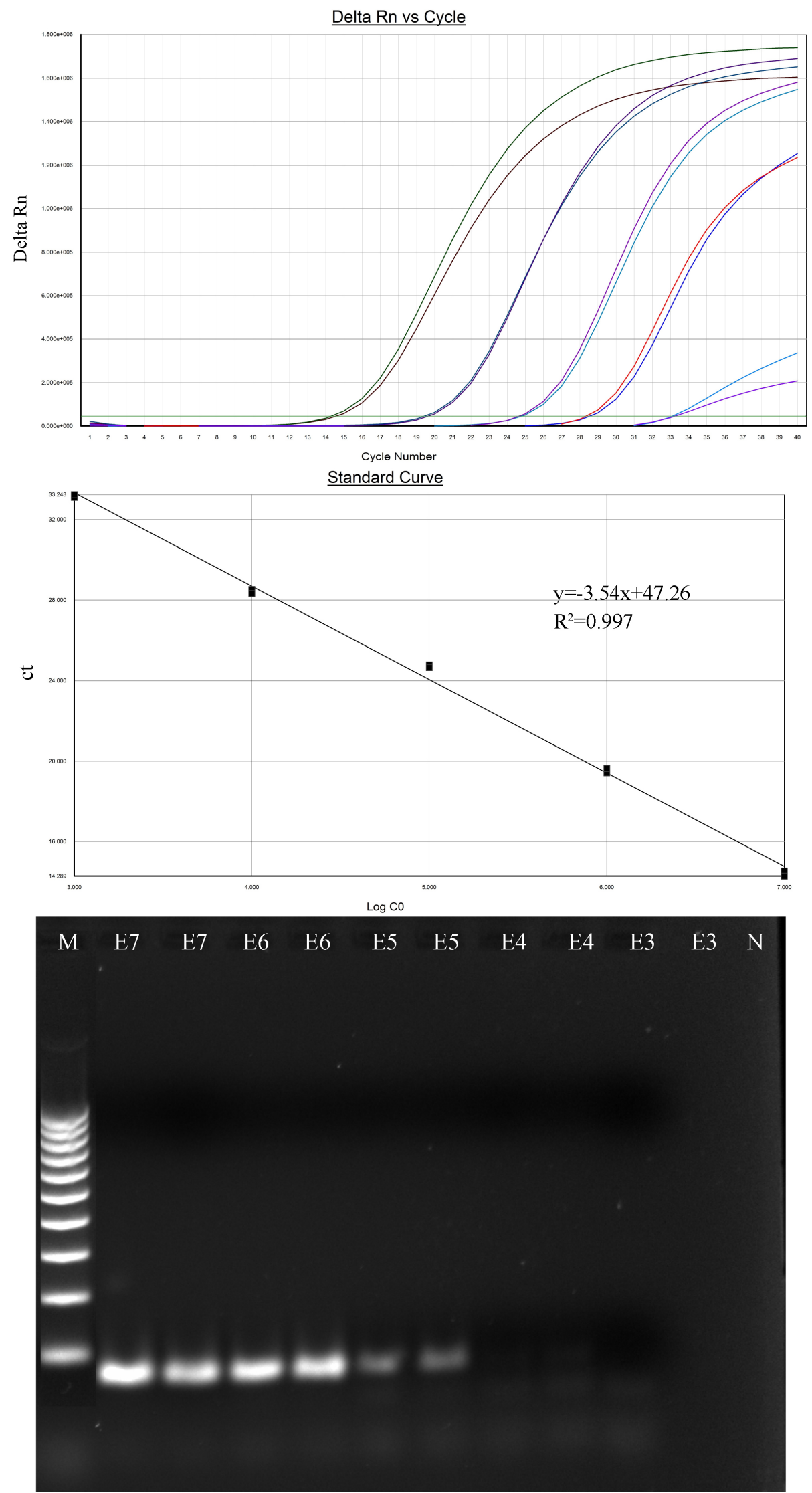


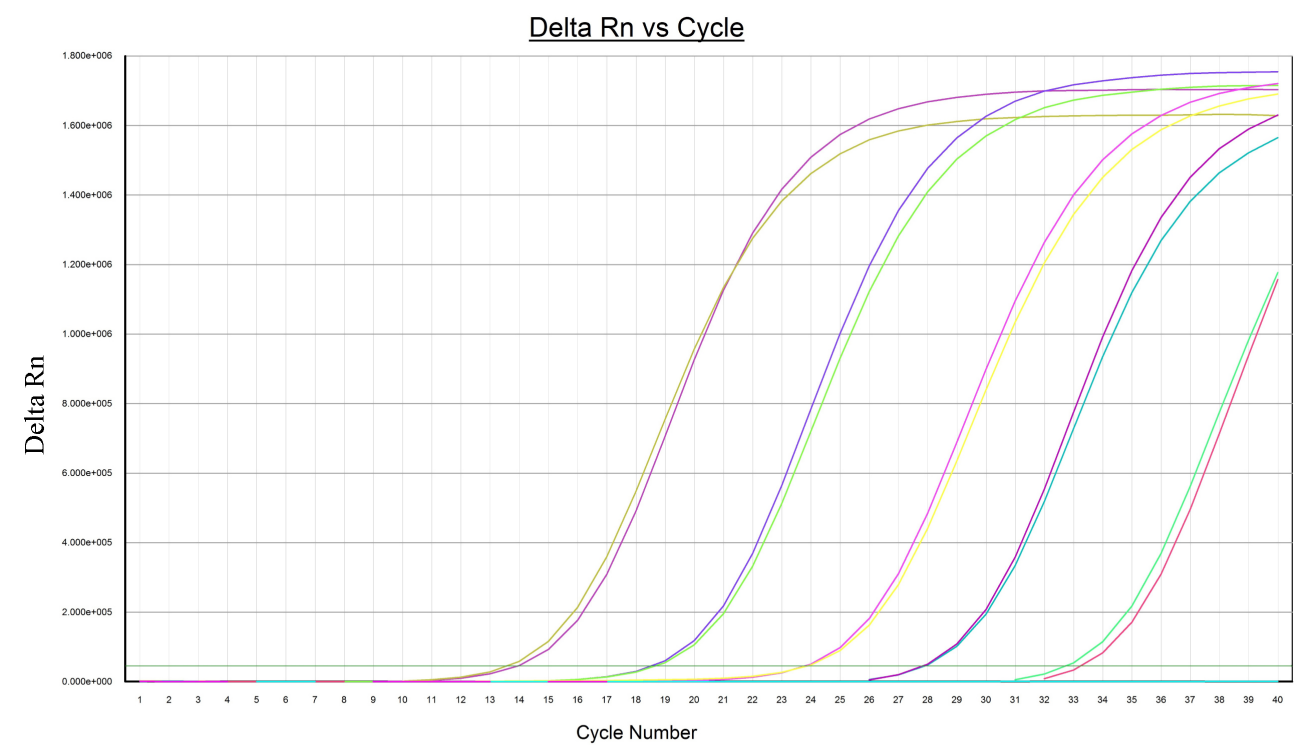

Standard Curve
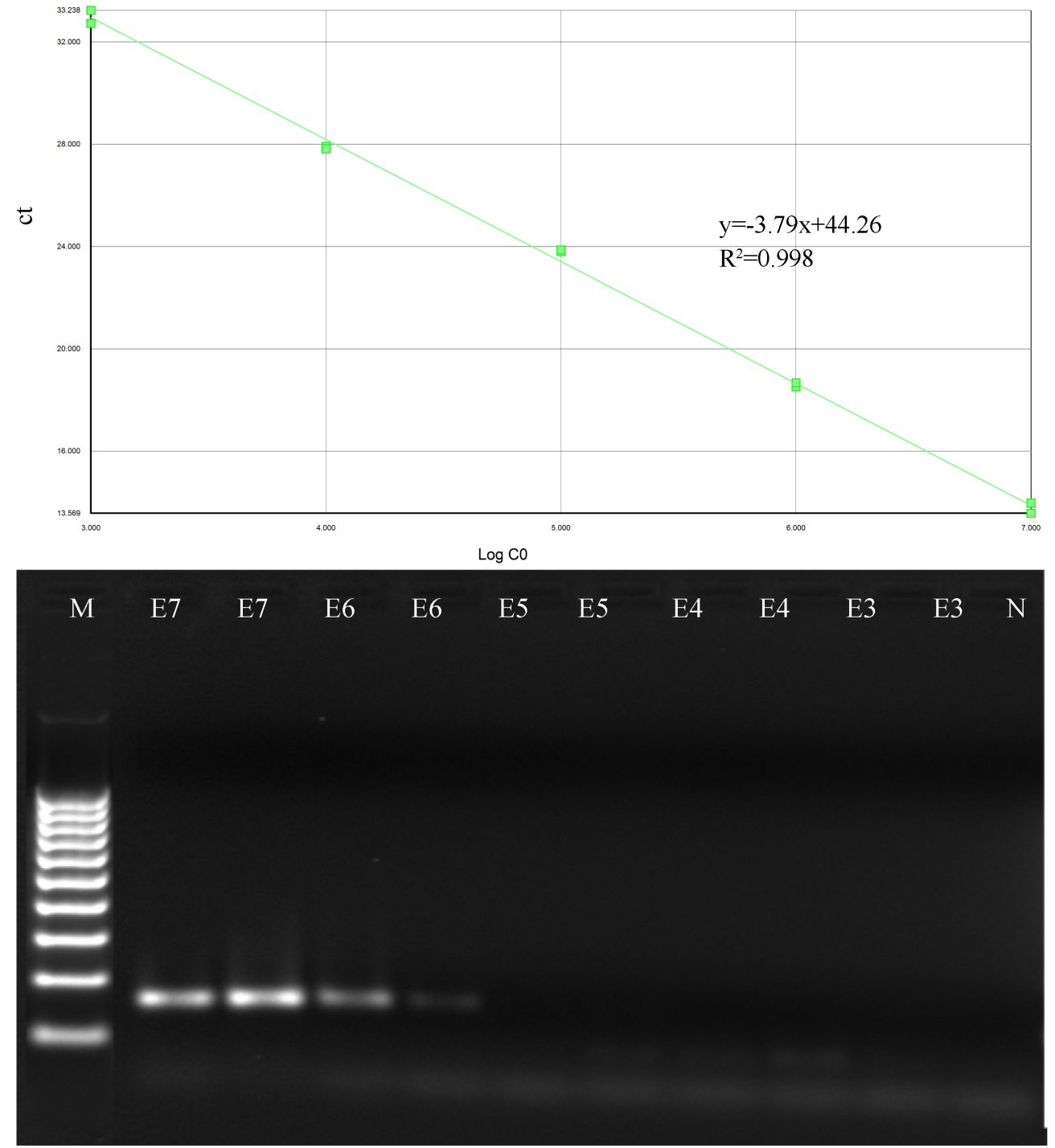

(h) 

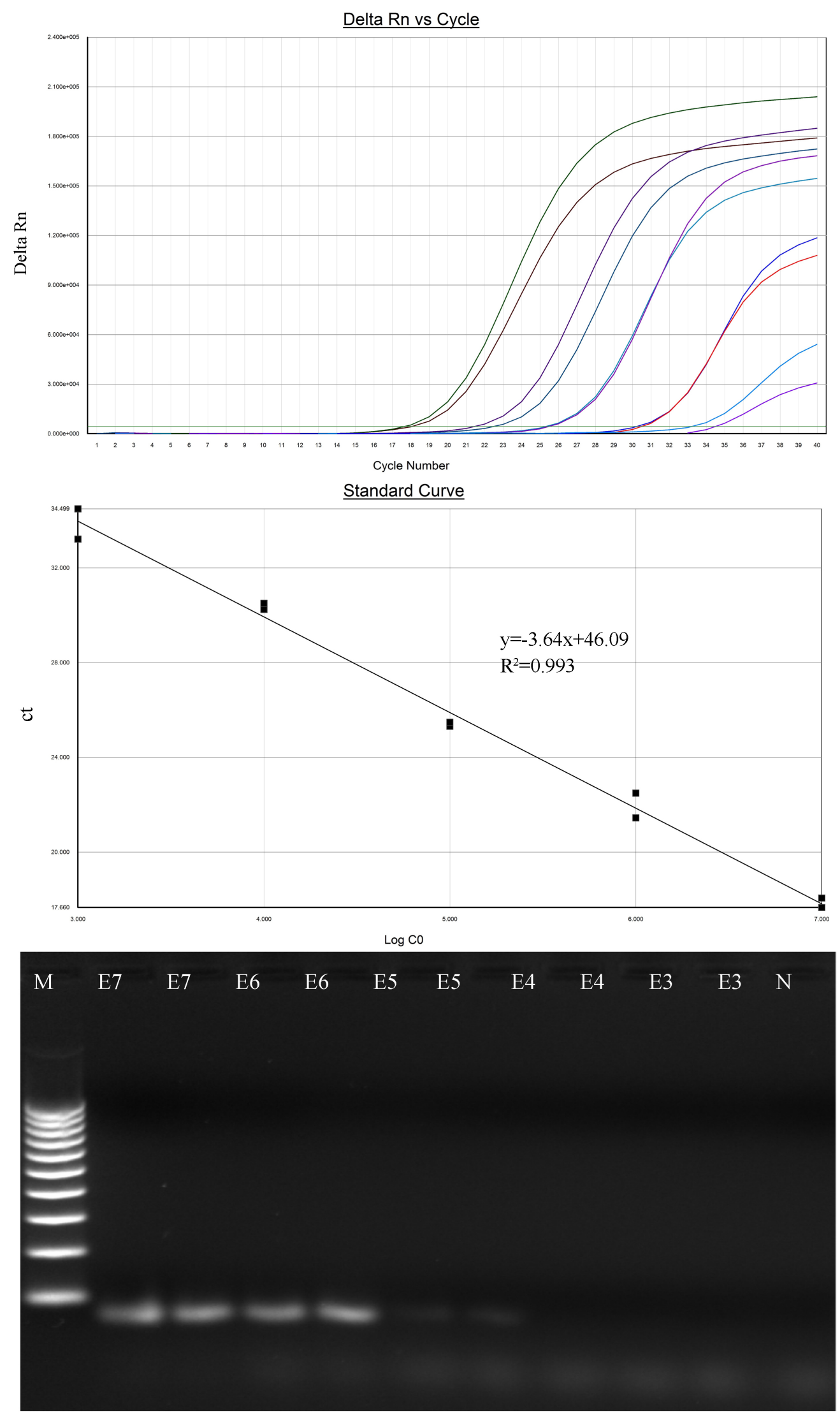

(i) 

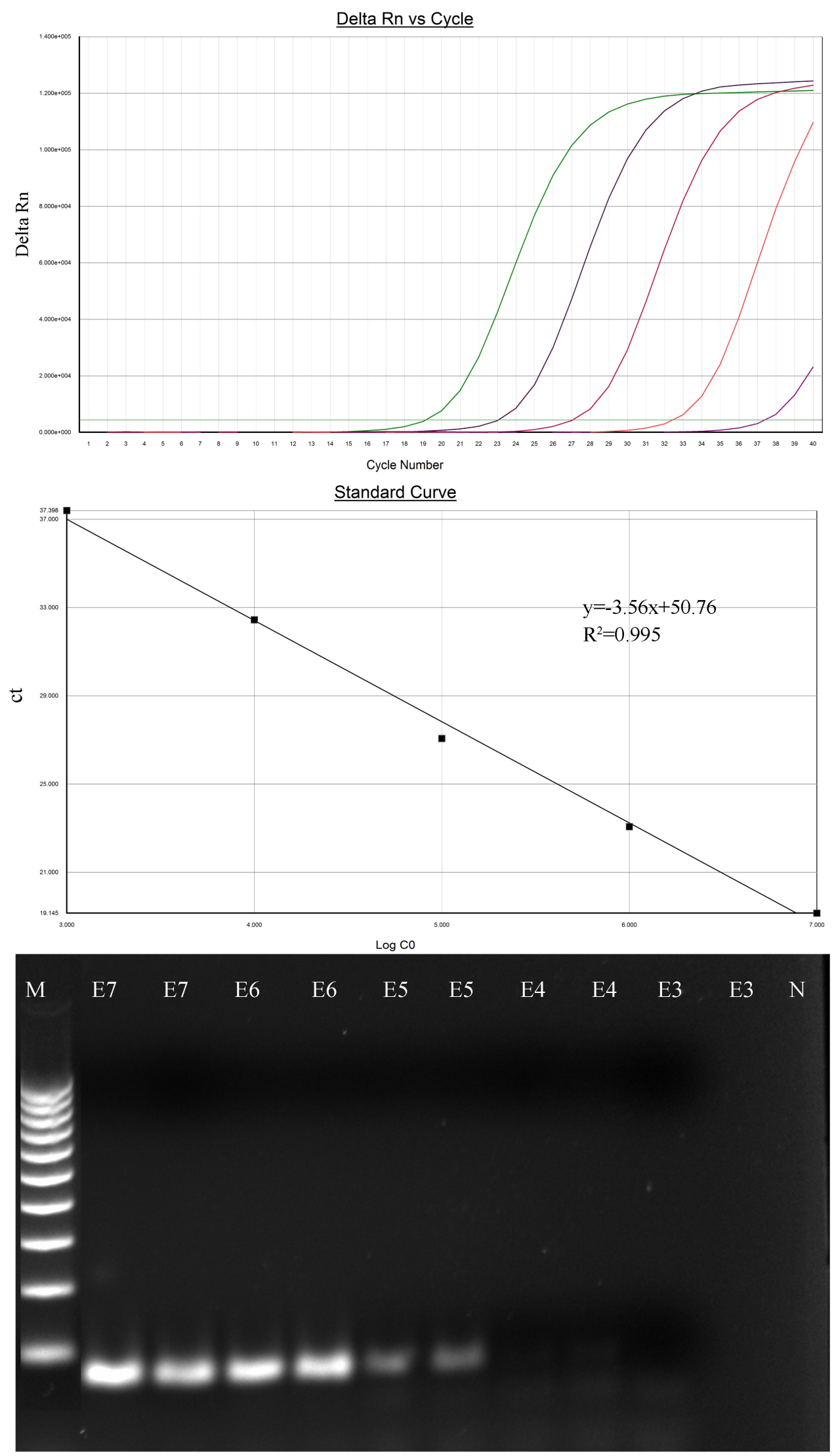

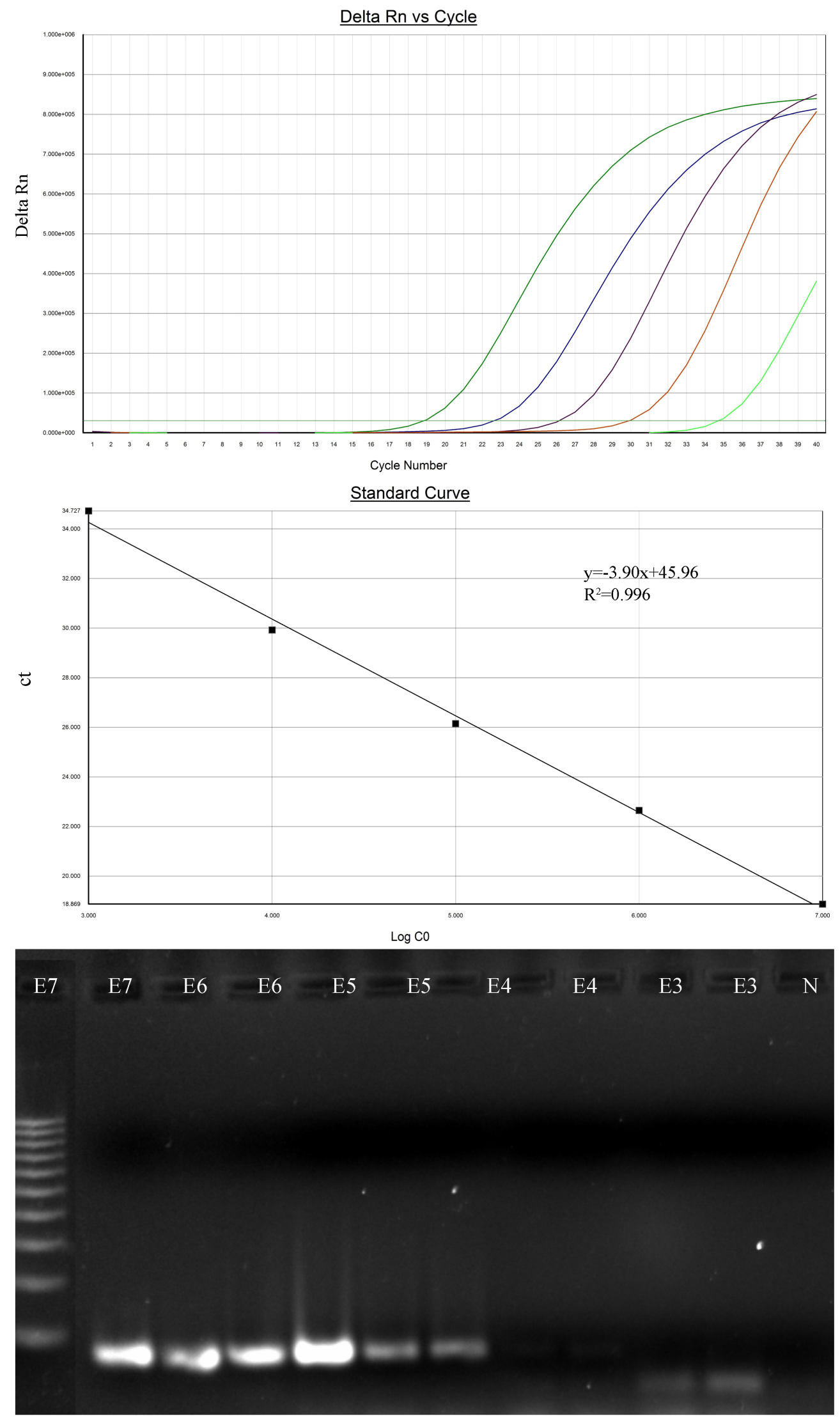

(k) 

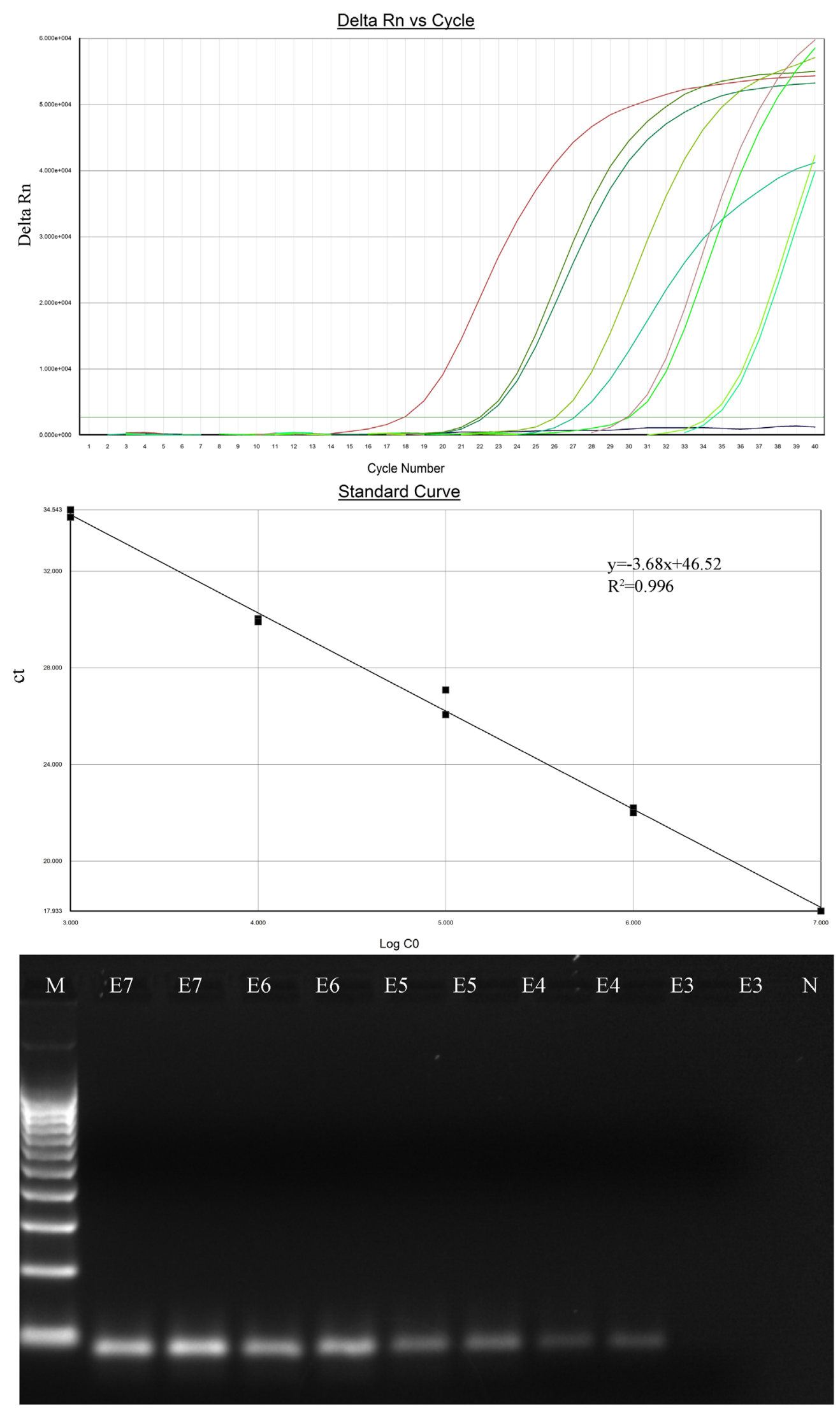

(1) 
Delta Rn vs Cycle

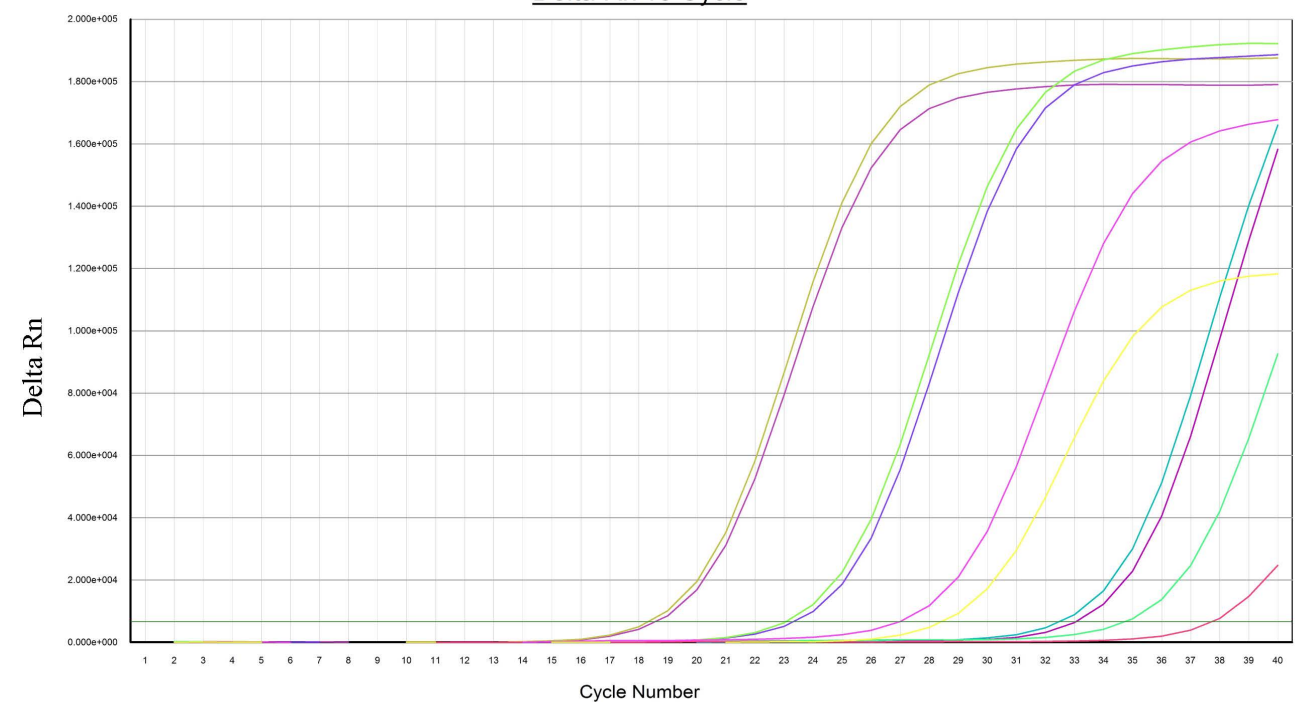

Standard Curve

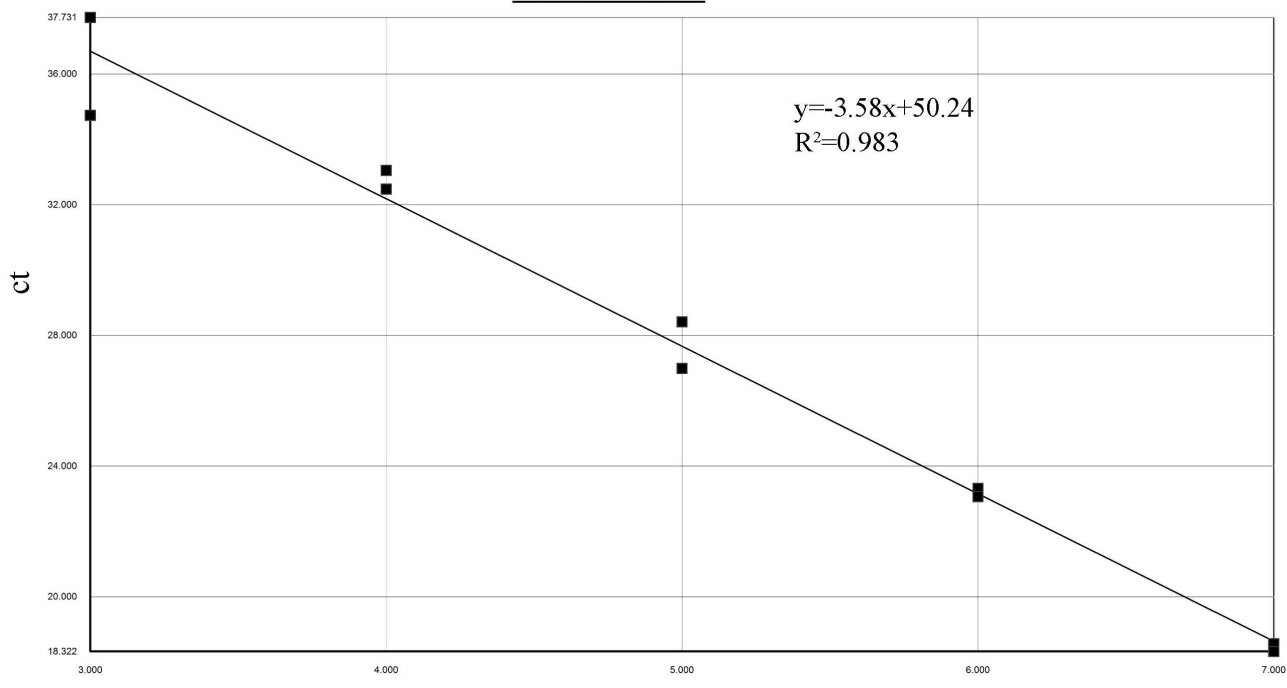

$\log \mathrm{CO}$

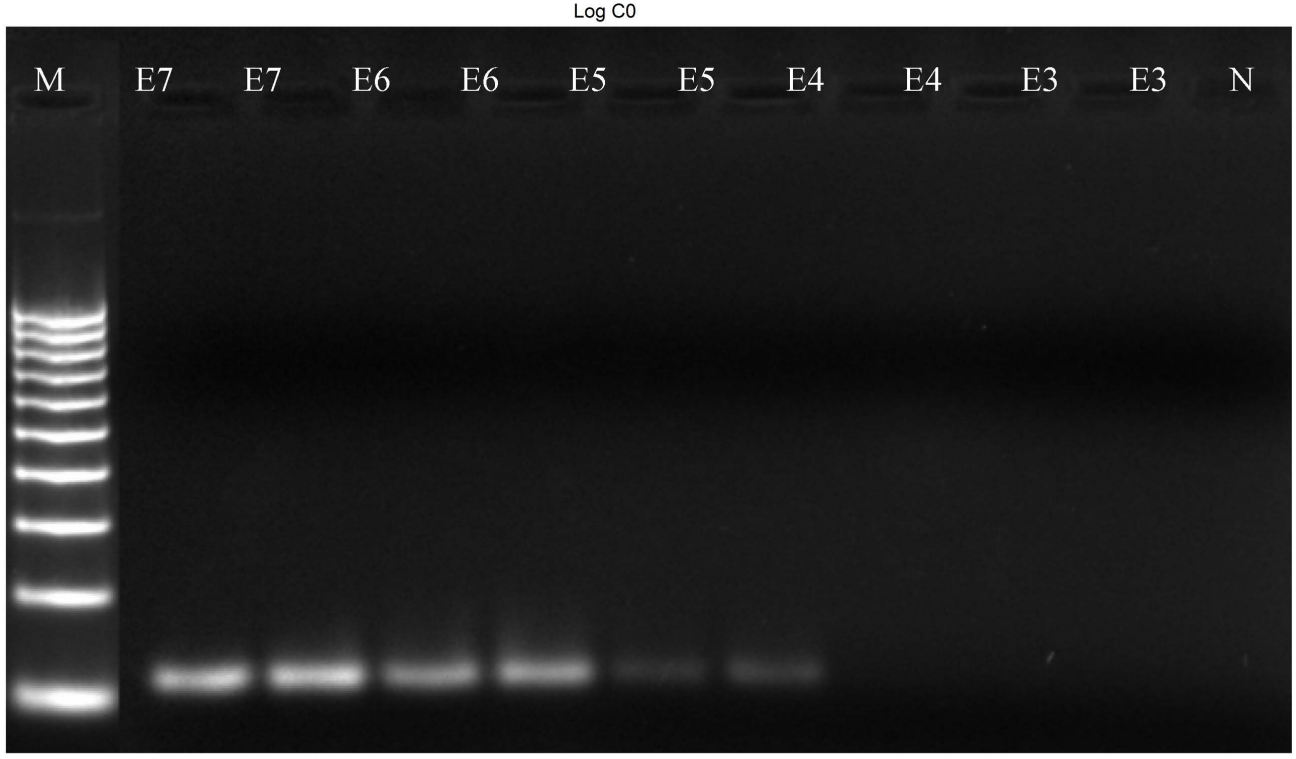

(m) 

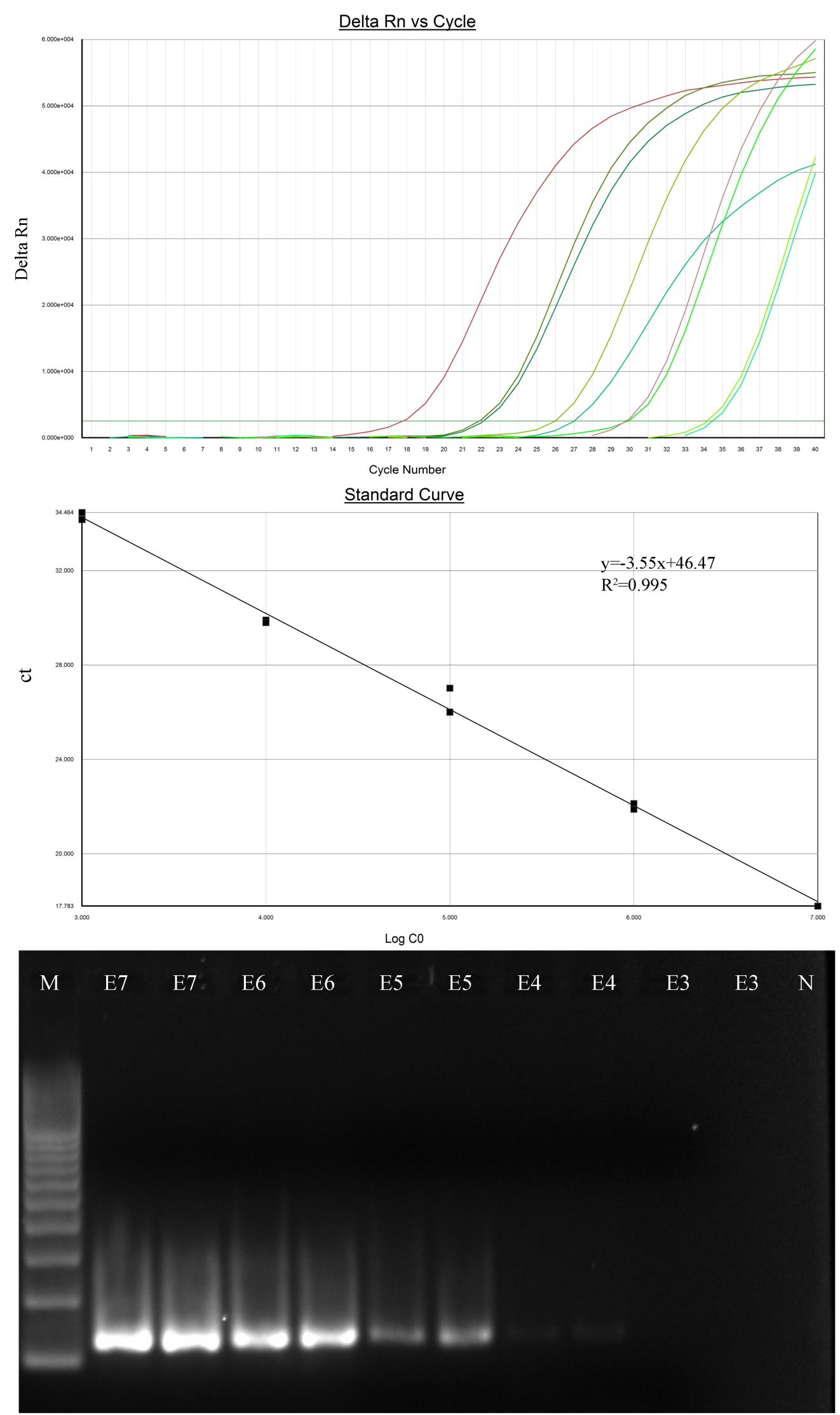

(n) 

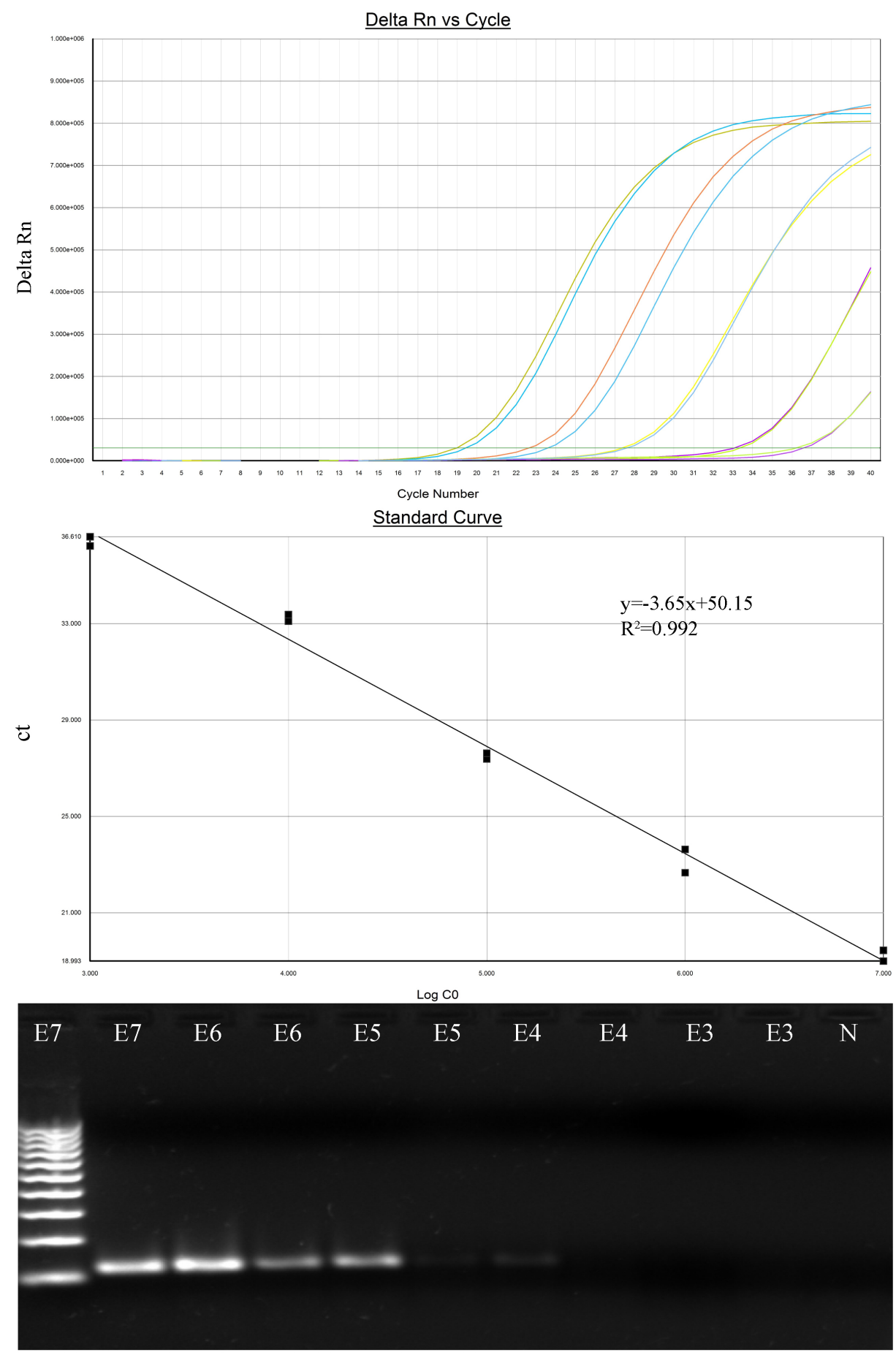

(o)

Figure 1. Amplification plots and standard curves of multiplex one-step qRT-PCR assays and comparison with RT-PCR assays. The multiplex one-step qRT-PCR assays and RT-PCR assays were tested using synthesized in vitro target viral RNA transcripts ranging from $1.2 \times 10^{3}$ to $1.2 \times 10^{7}$ copies $/ \mathrm{mL}$. A PCR baseline subtractive curve fit view of the data is shown with relative fluorescence units (RFUs) plotted against cycle numbers. Standard curves generated from the Ct values obtained against known concentrations, the coefficient of determination (R2) and slope of the regression curve for each assay are indicated. M:100 bp ladder; E3-E7: E3,1.0 × 10 3 , E4, $1.0 \times 10^{4}, \mathrm{E} 5,1.0 \times 10^{5}$, E6,1.0 $\times 10^{6}$, E7, $1.0 \times 10^{7}$; A-O group: A group, EEEV, B group, WEEV, C group, VEEV, D group, CHIKV, E group, MVEV, F group, SLEV, G group, WNV, H group, JEV, I group, CEV, J group, LCV, K group, POWV, L group, TBEV, M group, TOSV, N group, RVFV, O group, DENV. 
A total of 150 RNA samples which contained $8 \mathrm{CHIKV}$ patients, $20 \mathrm{JEV}$ patients and $13 \mathrm{TBEV}$ patients were tested using the multiplex one-step real-time qRT-PCR assays, the assay sensitivity was $100 \%$ with all the tested samples. The result showed 8 positive (8/8) in Group B, 20 positive (20/20) in Group D, 13 positive (13/13) in Group F, and the healthy human sera were negative (Table 5).
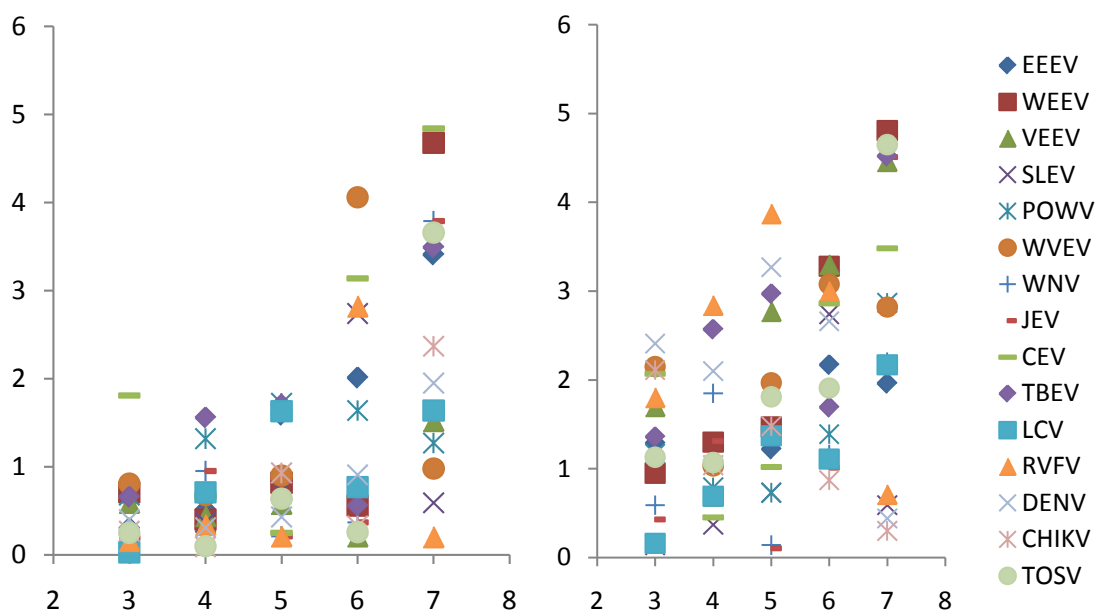

Figure 2. Coefficients of variation of Ct values in the multiplex one-step qRT-PCR assays. The multiplex one-step real-time RTPCR assays were performed in three independent experiments of replicates. The Coefficients of variation (CV) of Ct values were calculated in both intra-assays (A) and inter-assays (B), and showed all less than 5\%.

Table 3. Specificity analysis using in vitro transcribed viral RNAs.

\begin{tabular}{|c|c|c|c|c|c|c|c|c|c|c|c|c|c|c|c|}
\hline \multirow{2}{*}{ Assay } & \multicolumn{15}{|c|}{ In vitro transcribed target viral RNA $\left(1 \times 10^{6}\right.$ copies $\left./ \mu \mathrm{L}\right)$} \\
\hline & EEEV & WEEV & VEEV & CHIKV & MVEV & SLEV & WNV & JEV & $\mathrm{CEV}$ & $\mathrm{LCV}$ & POWV & TBEV & TOSV & RVFV & DENV \\
\hline EEEV & 21.18 & - & - & - & - & - & - & - & - & - & - & - & - & - & - \\
\hline WEEV & - & 20.69 & - & - & - & - & - & - & - & - & - & - & - & - & - \\
\hline VEEV & - & - & 20.10 & - & - & - & - & - & - & - & - & - & - & - & - \\
\hline CHIKV & - & - & - & 20.53 & - & - & - & - & - & - & - & - & - & - & - \\
\hline MVEV & - & - & - & - & 18.04 & - & - & - & - & - & - & - & - & - & - \\
\hline SLEV & - & - & - & - & - & 17.86 & - & - & - & - & - & - & - & - & - \\
\hline WNV & - & - & - & - & - & - & 18.49 & - & - & - & - & - & - & - & - \\
\hline JEV & - & - & - & - & - & - & - & 18.05 & - & - & - & - & - & - & - \\
\hline $\mathrm{CEV}$ & - & - & - & - & - & - & - & - & 20.12 & - & - & - & - & - & - \\
\hline LCV & - & - & - & - & - & - & - & - & - & 21.46 & - & - & - & - & - \\
\hline POWV & - & - & - & - & - & - & - & - & - & - & 20.65 & - & - & - & - \\
\hline TBEV & - & - & - & - & - & - & - & - & - & - & - & 20.13 & - & - & - \\
\hline TOSV & - & - & - & - & - & - & - & - & - & - & - & - & 20.52 & - & - \\
\hline RVFV & - & - & - & - & - & - & - & - & - & - & - & - & - & 20.83 & - \\
\hline DENV & - & - & - & - & - & - & - & - & - & - & - & - & - & - & 23.29 \\
\hline
\end{tabular}


Table 4. Specificity analysis using viral isolates and healthy human sera.

\begin{tabular}{|c|c|c|c|c|c|c|c|}
\hline \multirow{2}{*}{ Assay } & \multicolumn{4}{|c|}{ Viral isolates } & \multicolumn{3}{|c|}{$\begin{array}{l}\text { Healthy human serum } \\
\text { (positive/tested) }\end{array}$} \\
\hline & WNV & JEV & DENV1-4 & CHIKV & TBEV & RVFV & \\
\hline EEEV & - & - & - & - & - & - & $0 / 150$ \\
\hline WEEV & - & - & - & - & - & - & $0 / 150$ \\
\hline VEEV & - & - & - & - & - & - & $0 / 150$ \\
\hline CHIKV & - & - & - & 20.69 & - & - & $0 / 150$ \\
\hline MVEV & - & - & - & - & - & - & $0 / 150$ \\
\hline SLEV & - & - & - & - & - & - & $0 / 150$ \\
\hline WNV & 19.26 & - & - & - & - & - & $0 / 150$ \\
\hline JEV & - & 18.73 & - & - & - & - & $0 / 150$ \\
\hline $\mathrm{CEV}$ & - & - & - & - & - & - & $0 / 150$ \\
\hline LCV & - & - & - & - & - & - & $0 / 150$ \\
\hline POWV & - & - & - & - & - & - & $0 / 150$ \\
\hline TBEV & - & - & - & - & 21.18 & - & $0 / 150$ \\
\hline TOSV & - & - & - & - & - & - & $0 / 150$ \\
\hline RVFV & - & - & - & - & - & 21.94 & $0 / 150$ \\
\hline DENV & - & - & $\begin{array}{l}21.47,21.12, \\
25.42,26.39-\end{array}$ & - & - & - & $0 / 150$ \\
\hline
\end{tabular}

Table 5. Evaluation of the multiplex real-time qRT-PCR assays using clinical specimens.

\begin{tabular}{ccccc}
\hline Group & Detected Viruses & $\begin{array}{c}\text { Patients sera } \\
\text { (positive/tested) }\end{array}$ & $\begin{array}{c}\text { Vectors tissues } \\
\text { (positive/tested) }\end{array}$ & $\begin{array}{c}\text { Healthy human sera } \\
\text { (positive/tested) }\end{array}$ \\
\hline B & CHIKV & $8 / 8$ & - & $0 / 150$ \\
& VEEV & - & - & $0 / 150$ \\
D & WNV & - & - & $0 / 150$ \\
& JEV & $20 / 20$ & $6 / 112$ & $0 / 150$ \\
F & POWV & - & - & $0 / 150$ \\
& TBEV & $13 / 13$ & $2 / 38$ & $0 / 150$ \\
H & DENV & $45 / 45$ & $2 / 112$ & $0 / 150$ \\
& IC & - & - & - \\
\hline
\end{tabular}

The test of 45 sera collected from Dengue patients showed 95.6\% sensitivity (43 out of 45 detected DENV positive) with only two negative samples (Table 5). For these 112 mosquito pools, 6 pools were JEV positive and 2 pools were DENV positive respectively, and for the 38 ticks, 2 were positive. These results of vector samples were validated as the same as the above results by RT-PCR or sequencing. Also, there were no false positive results observed in the unrelated patient sera and healthy humans era, suggesting $100 \%$ specificity in all the three tested groups of multiplex assays (Table 5). 


\section{Discussion}

There are many central nervous system diseases and conditions, including infections of the central nervous system such as encephalitis. Arboviral Encephalitis Viruses are member of animal viruses, including flaviviruses, phlebovirus, orthobunyavirus, and the alphaviruses. And mostly Arboviral Encephalitis Viruses may cause encephalitis in a minority of infected humans.

Due to the unspecific clinical characters at the early phase of CNS, detection of Arboviral Encephalitis Viruses infection is very importance in early diagnosis, and it is important for successful clinical management. There have several methods were reported for detection of Arboviral Encephalitis Viruses. For example Double Antibody Sandwich ELISA was used to detect WNV [30], and detection of antibodies to EEEV, WNV, TURV [31]. Also, qRT-PCR or Multiplex qRT-PCR as Superiority methods were used to detect of Arboviral Encephalitis Viruses. It has reported a multiplex Taqmanq RT-PCR based assay was used to detect RNA from WEEV, SLEV, and WNV strains [32], RT-PCR was used to detect WNV in whole blood for diagnosis of acute infection [33]. In this study, multiplex quantitative real-time RT-PCR assays for detection of 15 arboviral encephalitis viruses which could be carried out in the same plate was developed. And the multiplex one-step qRT-PCR assays covered nearly all the important viral pathogens that cause arboviral encephalitis, including Eastern equine encephalitis virus (EEEV), Western Equine Encephalitis virus (WEEV), Venequilan Equine Encephalitis virus (VEEV), Japanese Encephalitis virus (JEV), Saint Louis Encephalitis virus (SLEV), Murray Valley Encephalitis virus (MVEV), West Nile virus (WNV), Powassan virus (POWV), California Encephalitis virus (CEV), La Crosse virus (LCV), Tick-borne Encephalitis virus (TBEV), Rift Valley Fever virus (RVFV), Toscana virus (TOSV), Dengue virus (DENV), Chikungunya virus (CHIKV). Also, internal control was set and performed in the multiplex qRT-PCR assays. Single-plex one-step qRT-PCR assays, multiplex one-step qRT-PCR assays and one-step RT-PCR assays were compared for sensitivity for the 15 species viruses using the in vitro transcribed viral RNAs. All the assays showed standard curves with high amplification efficiencies and strong linear correlations. In most multiplex assays, the LODs were similar to that in the single-plex assays. And duplex qRT-PCR was 1000-fold more sensitive than one-step RT-PCR for the amplification of EEEV, WEEV, VEEV, RVFV, JEV and TOSV, and was 100-fold more sensitive than one-step RT-PCR for that of WNV, CEV, LCV, POWV, TBEV and DENV, and was 10-fold more sensitive than one-step RT-PCR for that of MVEV and CHIKV. Therefore, the overall of the sensitivities of multiplex assays was satisfactory, which made it possible to screen arboviral encephalitis pathogens in one step without requiring of large amount of clinical samples. Besides, the reproducibility of the multiplex one-step real-time qRT-PCR assays for detection of each viral species, duplicates of the assay within or between runs were performed. The $\mathrm{CV}$ of $\mathrm{Ct}$ values were all less than $6 \%$ in each dilution of synthesized viral RNAs for both intra-assays 
and inter-assays, suggesting that the multiplex assays were of good reproducibility. To verify the Multiplex One-Step Real-time TaqManqRT-PCR Assays were detecting infectious virus, total of 150 human serum RNA samples were examined. The result showed that the assay sensitivity was $100 \%$ with all the tested samples and there were no false positive results observed in the unrelated patient sera and healthy humans era. Also, in this study, IC was used to monitor all assay results. All the negative results were validated through observation of the amplifications of IC to avoid the false negative result. In this way, IC increased the assay's sensitivity. The assay sensitivity and specificity for diagnosis of JEV, TBEV, DENV, CHIKV virus infection inpatient sera were reliable and desirable. The specificity and reproducibility of the assays were demonstrated and the sensitivity of the systems was acceptable. Furthermore, evaluation with clinical samples of patients and vectors showed the reliable specificities and sensitivities for laboratory detection of the infections with these viruses and provided potential use for clinical diagnosis and vector surveillance.

\section{Conclusions}

In conclusion, the comprehensive multiplex one-step real-time TaqManqRT-PCR assays for rapid detection of 15 viruses was established and evaluated in this study. The developed multiplex one-step real-time qRT-PCR assay was tested using different simulate samples and showed excellent parameters in the followed statistical analysis. Therefore, this assay proved to be specific, sensitive and, apparently, convenient for rapid and simultaneous identification in laboratory, and could be certainly extended to routine diagnosis and epidemiological detection of arboviral encephalitis infections.

The arboviral encephalitis virus panel with IC developed in this study was found to be highly specific and sensitive in the detection of 15 encephalitis viruses from clinical specimens and vector tissues. The use of IC prevented false negative readings and improved accuracy of the assay. The panel can be a great aid to clinical management, vector surveillance and outbreak response of CNS in the future.

\section{Acknowledgements}

The authors thank Dr. Bo Zhang, Dr. Hongping Wei and staff of Wuhan Institute of Virology for their technical assistance and for virus strains. We thank Dr. Yuping Luo for her linguistic advice.

\section{Ethical Consideration}

According to the medical research regulation of National Health and Family Planning Commission, China, all studies involved in human samples were reviewed and approved by the ethics committee of Ningbo International Travel Healthcare Center, which uses international guidelines to ensure confidentiality, anonymity, and informed consent. The written informed consent was agreed by 
the donors.

\section{Competing Interests}

The authors have declared no competing financial interests exist.

\section{Funding}

This work was supported by Project of Zhejiang Provincial Natural Science Foundation (LY16H260004) and Project of Ningbo Entry-exit Inspection and Quarantine Bureau Science and Technology Program (Y2015-15).

\section{References}

[1] Anderson, P.D. and Bokor, G. (2012) Bioterrorism: Pathogens as Weapons. Journal of Pharmacy Practice, 25, 521-529. https://doi.org/10.1177/0897190012456366

[2] Mackay, I.M., Arden, K.E. and Nitsche, A. (2002) Real-Time PCR in Virology. Nucleic Acids Research, 30, 1292-1305. https://doi.org/10.1093/nar/30.6.1292

[3] Espy, M.J., Uhl, J.R., Sloan, L.M., Buckwalter, S.P., Jones, M.F., Vetter, E.A., Yao, J.D., Wengenack, N.L., Rosenblatt, J.E., Cockerill 3rd, F.R. and Smith, T.F. (2006) Real-Time PCR in Clinical Microbiology: Applications for Routine Laboratory Testing. Clinical Microbiology Reviews, 19, 165-256. https://doi.org/10.1128/CMR.19.1.165-256.2006

[4] Armstrong, P.M. and Andreadis, T.G. (2013) Eastern Equine Encephalitis Virus-Old Enemy, New Threat. New England Journal of Medicine, 368, 1670-1673. https://doi.org/10.1056/NEJMp1213696

[5] Zink, S.D., Jones, S.A., Maffei, J.G. and Kramer, LD. (2013) Quadraplex qRT-PCR Assay for the Simultaneous Detection of Eastern Equine Encephalitis Virus and West Nilevirus. Diagnostic Microbiology and Infectious Disease, 77, 129-132. https://doi.org/10.1016/j.diagmicrobio.2013.06.019

[6] Brault, A.C., Fang, Y. and Reisen, W.K. (2015) Multiplex qRT-PCR for the Detection of Western Equine Encephalomyelitis, St. Louis Encephalitis, and West Nile Viral RNA in Mosquito Pools (Diptera: Culicidae). Journal of Medical Entomology, 52, 491-499. https://doi.org/10.1093/jme/tjv021

[7] Bergren, N.A., Auguste, A.J., Forrester, N.L., Negi, S.S., Braun, W.A. and Weaver, S.C. (2014) Western Equine Encephalitis Virus: Evolutionary Analysis of a Declining Alphavirus Based on Complete Genome Sequences. Journal of Virology, 88, 9260-9267. https://doi.org/10.1128/JVI.01463-14

[8] Gutiérrez, S., Thébaud, G., Smith, D.R., Kenney, J.L. and Weaver, S.C. (2015) Demographics of Natural Oral Infection of Mosquitos by Venezuelan Equine Encephalitis Virus.

[9] Moureau, G., Temmam, S., Gonzalez, J.P., Charrel, R.N., Grard, G. and de Lamballerie, X. (2007) A Real-Time RT-PCR Method for the Universal Detection and Identification of Flavi Viruses. Vector-Borne and Zoonotic Diseases, 7, 467-477. https://doi.org/10.1089/vbz.2007.0206

[10] Oyer, R.J., David Beckham, J. and Tyler, K.L. (2014) West Nile and St. Louis Encephalitis Viruses. HandbClin Neurol., 123, 433-447. https://doi.org/10.1016/B978-0-444-53488-0.00020-1

[11] Kopp, A., Gillespie, T.R., Hobelsberger, D., Estrada, A., Harper, J.M., Miller, R.A., Eckerle, I., Müller, M.A., Podsiadlowski, L., Leendertz, F.H., Drosten, C. and Jung- 
len, S. (2013) Provenance and Geographic Spread of St. Louis Encephalitis Virus. MBio, 4, e00322-13. https://doi.org/10.1128/mBio.00322-13

[12] Kilpatrick, A.M. and Pape, W.J. (2013) Predicting Human West Nile Virus Infections with Mosquito Surveillance Data. American Journal of Epidemiology, 178, 829-835. https://doi.org/10.1093/aje/kwt046

[13] Kovalev, S.Y. and Mukhacheva, T.A. (2014) Tick-Borne Encephalitis Virus Subtypes Emerged through Rapid Vector Switches Rather than Gradual Evolution. Ecology and Evolution, 4, 4307-4316. https://doi.org/10.1002/ece3.1301

[14] Veje, M., Studahl, M., Norberg, P., Roth, A., Möbius, U., Brink, M. and Bergström, T. (2014) Detection of Tick-Borne Encephalitis Virus RNA in Urine. Journal of Clinical Microbiology, 52, 4111-4112. https://doi.org/10.1128/JCM.02428-14

[15] Achazi, K., Nitsche, A., Patel, P., Radonić, A., DonosoMantke, O. and Niedrig, M. (2011) Detection and Differentiation of Tick-Borne Encephalitis Virus Subtypes by a Reverse Transcription Quantitative Real-Time PCR and Pyrosequencing. Journal of Virological Methods, 171, 34-39. https://doi.org/10.1016/j.jviromet.2010.09.026

[16] Ananthan, D., Shah, S., Haseer-Koya, H. and Patel, A. (2014) Powasson Virus Causing Tick-Borne Encephalitis: A Diagnostic Dilemma. QJM, 107, 909-910. https://doi.org/10.1093/qjmed/hcu082

[17] Reese, S.M., Blitvich, B.J., Blair, C.D., Geske, D., Beaty, B.J. and Black, W.C. (2008) Potential for La Crosse Virus Segment Reassortment in Nature. Virology Journal, 30, 16. https://doi.org/10.1186/1743-422X-5-164

[18] Maquart, M., Temmam, S., Héraud, J.M., Leparc-Goffart, I., Cêtre-Sossah, C., Dellagi, K., Cardinale, E. and Pascalis, H. (2014) Development of Real-Time RT-PCR for the Detection of Low Concentrations of Rift Valley Fever Virus. Journal of Virological Methods, 195, 92-99. https://doi.org/10.1016/j.jviromet.2013.10.001

[19] Mwaengo, D., Lorenzo, G., Iglesias, J., Warigia, M., Sang, R., Bishop, R.P. and Brun, A. (2012) Detection and Identification of Rift Valley Fever Virus in Mosquito Vectors by Quantitative Real-Time PCR. Virus Research, 169, 137-143. https://doi.org/10.1016/j.virusres.2012.07.019

[20] Charrel, R.N., Bichaud, L. and de Lamballerie, X. (2012) Emergence of Toscana Virus in the Mediterranean Area. World Journal of Virology, 1, 135-141. https://doi.org/10.5501/wjv.v1.i5.135

[21] Williams, D.T., Diviney, S.M., Niazi, A.U., Durr, P.A., Chua, B.H., Herring, B., Pyke, A., Doggett, S.L., Johansen, C.A. and Mackenzie, J.S. (2015) Molecular Epidemiology and Evolution of Murray Valley Encephalitis Virus: Recent Emergence of Distinct Sub-Lineages of the Dominant Genotype 1. PLOS Neglected Tropical Diseases, 9, e0004240. https://doi.org/10.1371/journal.pntd.0004240

[22] Gong, R., Wang, H.H., Qin, H., Guo, X.P. and Ma, X.J. (2015) Visual Detection of Murray Valley Encephalitis Virus by Reverse Transcription Loop-Mediated Isothermal Amplification. Biomedical and Environmental Sciences, 28, 227-230.

[23] Williams, D.T., Diviney, S.M., Corscadden, K.J., Chua, B.H. and Mackenzie, J.S. (2014) Complete Genome Sequences of the Prototype Isolates of Genotypes 2, 3, and 4 of Murray Valley Encephalitis Virus. Genome Announcements, 2, e00581. https://doi.org/10.1128/genomeA.00581-14

[24] Chancey, C., Grinev, A., Volkova, E. and Rios, M. (2015) The Global Ecology and Epidemiology of West Nile Virus. BioMed Research International, 2015, Article ID: 376230. https://doi.org/10.1155/2015/376230

[25] Phu Ly, M.H., Takamatsu, Y., Nabeshima, T., Pham Hoai, L.L., Pham Thi, H., Dang 
Thi, D., Nguyen, N.L., Nguyen Thi, T.T., Le Thi, Q.M., Buerano, C.C., Morita, K. and Hasebe, F. (2015) Isolation of Dengue Serotype 3 Virus from the Cerebrospinal Fluid of an Encephalitis Patient in Hai Phong, Vietnam in 2013. Journal of Clinical Virology, 70, 93-96. https://doi.org/10.1016/j.jcv.2015.07.295

[26] Christo, P.P. (2015) Encephalitis by Dengue Virus and Other Arboviruses. Arquivos de Neuro-Psiquiatria, 73, 641-643. https://doi.org/10.1590/0004-282X20150108

[27] Shaikh, N.J., Raut, C.G., Sinha, D.P. and Manjunath, M.J. (2015) Detection of Chikungunya Virus from a Case of Encephalitis, Bangalore, Karnataka State. Indian Journal of Medical Microbiology, 33, 454-455.

[28] Nelson, J., Waggoner, J.J., Sahoo, M.K., Grant, P.M. and Pinsky, B.A. (2014) Encephalitis Caused by Chikungunya Virus in a Traveler from the Kingdom of Tonga. Journal of Clinical Microbiology, 52, 3459-3461.

https://doi.org/10.1128/JCM.01288-14

[29] Felder, E. and Wölfel, R. (2012) Development of a Versatile and Stable Internal Control System for RT-qPCR Assays. Journal of Virological Methods, 208, 33-40. https://doi.org/10.1016/j.jviromet.2014.07.028

[30] Ding, X.-X., Li, X.-F., Deng, Y.-Q., Guo, Y.-H., Hao, W., et al. (2014) Development of a Double Antibody Sandwich ELISA for West Nile Virus Detection Using Monoclonal Antibodies against Non-Structural Protein 1. PLOS ONE, 9, e108623. https://doi.org/10.1371/journal.pone.0108623

[31] Pedersen, K., Marks, D.R., Wang, E., Eastwood, G., et al. (2016) Widespread Detection of Antibodies to Eastern Equine Encephalitis, West Nile, St. Louis Encephalitis, and Turlock Viruses in Various Species of Wild Birds from Across the United States. The American Journal of Tropical Medicine and Hygiene, 95, 206-211. https://doi.org/10.4269/ajtmh.15-0840

[32] Brault, A.C., Fang, Y., Reisen, W.K., et al. (2015) Multiplex qRT-PCR for the Detection of Western Equine Encephalomyelitis, St. Louis Encephalitis, and West Nile Viral RNA in Mosquito Pools (Diptera: Culicidae). Journal of Medical Entomology, 52, 491-499. https://doi.org/10.1093/jme/tjv021

[33] Lustig, Y., Mannasse, B., Koren, R., Katz-Likvornik, S., et al. (2016) Superiority of West Nile Virus RNA Detection in Whole Blood for Diagnosis of Acute Infection. Journal of Clinical Microbiology, 54, 2294-2297.

https://doi.org/10.1128/JCM.01283-16 


\section{Supplementary}

Table S1. GenBank accession numbers of arboviral encephalitis virus sequences aligned in this study.

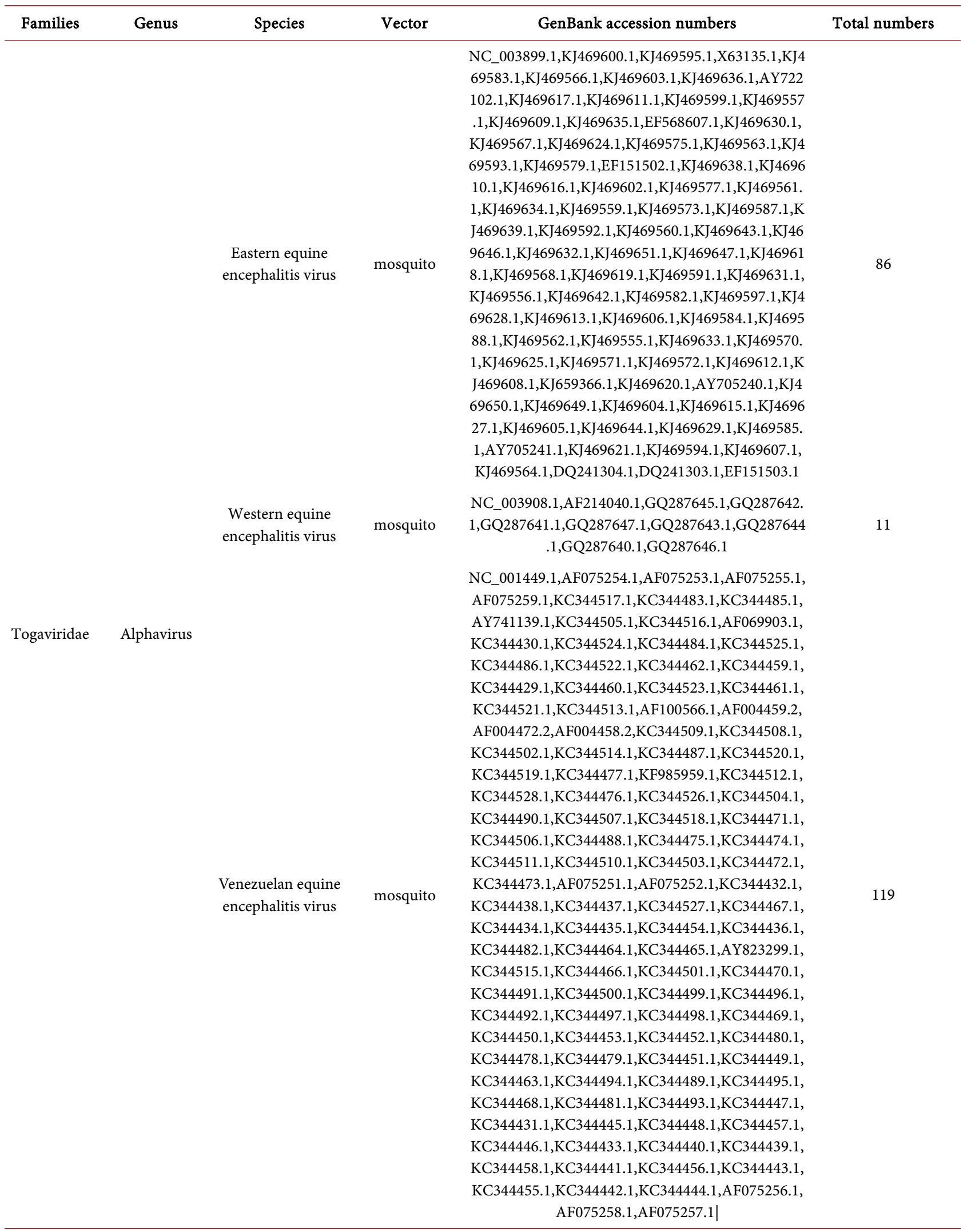


Chikungunya virus

Japanese encephalitis virus
NC_004162.2,KJ451623.1,KJ451622.1,KJ451624.1,KF31 8729.1,FJ807897.1,FN295483.3,FN295484.2,EU703760.1 ,EU703761.1,EU703759.1,EU703762.1,HE806461.1,HM 045814.1,HM045808.1,HM045796.1,HM045787.1,HM0 45802.1,HM045789.1,HM045800.1,HM045790.1,HM04 5791.1,HM045797.1,EF452494.1,L37661.,EF452493.1,H M045810.1,HM045813.1,HM045803.1,HM045788.1,EF 027141.1,EF027140.1,JF274082.1,HM159390.1,HM1593 89.1,HM159388.1,HM159386.1,HM159387.1,HM15938 5.1,FJ445511.2,FJ445510.2,FJ000068.1,FJ000062.1,FJ000 065.1,EU564335.1,JN558836.1,JN558835.1,JN558834.1, EF210157.2,EF027138.1,FJ807896.1,GU908223.1,FJ4454 84.2,FJ445433.2,FJ445463.2,GU301779.1,KC862329.1,G U301781.1,FJ445430.2,GQ905863.1,FJ445502.2,FJ44544 3.2,FJ445445.2,FJ445431.2,FJ445432.2,JX088705.1,FN29 5485.3,FN295487.2,FJ807899.1,GU199353.1,GU199352. 1,GU301780.1,GQ428212.1,FJ000069.1,GQ428213.1,G mosquito Q428214.1,EU244823.2,HM045801.1,GU199350.1,GU1 89061.1,FJ513679.1,FJ513628.1,FJ513657.1,FJ513629.1,F J513637.1,FJ513635.1,FJ445428.2,AB455494.1,AB45549 3.1,FJ445427.2,EF027137.1,FJ000066.1,HM045799.1,GQ 428211.1,FJ000064.1,FJ000063.1,EU372006.1,FJ807898. 1,GQ428215.1,FJ513675.1,GU199351.1,FJ513654.1,FJ51 3645.1,FJ513673.1,FJ513632.1,FJ445426.2,FJ000067.1,H Q456254.1,HQ456253.1,HQ456252.1,HQ456251.1,DQ4 43544.2,EU564334.1,FJ959103.1,EF012359.1,EU037962. 1,FR717337.1,FR717336.1,HQ456255.1,EF027134.1,EF0 27136.1,EF027135.1,GQ428210.1,HM045794.1,HM1593 84.1,HM045823.1,HM045784.1,HM045812.1,EF027139. 1,HM045793.1,JQ067624.1,HM045822.1,AF369024.2,A F490259.3,HM045821.1,HM045806.1,HM045805.1,HM 045795.1,HM045792.1,HM045811.1,HM045809.1,HM0 45819.1,HM045818.1,HM045820.1,AY726732.1,HM045 807.1,HM045786.1,HM045816.1,HM045804.1,HM0457 98.1,HM045785.1,HM045815.1,HM045817.1 NC_001437.1,JF915894.1,HM596272.1,JF706274.1,JN38 1840.1,FJ495189.1,JN381839.1,JN381845.1,JN381844.1,J F706267.1,JN381836.1,JN381835.1,JN381837.1,JN38183 8.1,GU187972.1,JN381831.1,JN381832.1,JF706268.1,JN 381833.1,KC196115.1,JF499790.1,JQ031753.1,JF706277. 1,GU205163.1,JN381830.1,JN381834.1,JN381842.1,JN3 81841.1,AB241118.1,AB698909.1,AB698906.1,AB69890 5.1,AB698908.1,AB698907.1,AB853904.1,HM366552.1,J N381843.1,AB594829.1,JN381849.1,GU556217.1,EU693 899.1,EU429297.1,EU880214.1,AB830335.1,HQ893545. 1,JF706286.1,JF499789.1,JF499788.1,JF706271.1,JN3818 52.1,JN381850.1,HM228921.1,JF706270.1,JN381851.1,J N381846.1,AB241119.1,JF706281.1,JF706278.1,JN38184 8.1,JN381847.1,AY316157.1,JF706282.1,AF045551.2,GQ 902062.1,GQ902061.1,GQ902059.1,GQ902058.1,GQ902 060.1,JF706279.1,AF217620.1,AY303791.1,AY303792.1, AF254453.1,AF254452.1,AB196924.1,KF907505.1,AB19 6926.1,AB196923.1,AB196925.1,AF069076.1,JF706275.1 ,GQ918133.2,AY508813.1,AY508812.1,JF706280.1,AF0 98737.1,AF098736.1,AF098735.1,AF221500.1,AF221499 .1,AY303794.1,AY303793.1,AY303797.1,AY303796.1,A Y303798.1,AY303795.1,M18370.1,EF543861.1,AB55199 0.1,JN381869.1,GQ199609.1,AY585243.1,AY585242.1,A 


\section{Continued}

\begin{abstract}
Saint Louis encephalitis virus Murray Valley encephalitis virus
\end{abstract}

West Nile virus
B551992.1,AB551991.1,KF297916.1,KC915016.1,JN381 873.1,JF706269.1,JN381872.1,KC517497.1,D90194.,D9 0195.,JN604986.1,AF315119.1,JQ086762.1,JN864064.1, JQ086763.1,KF297915.1,AF416457.1,M55506.1,JN3818 70.1,EF623988.1,EF623989.1,AF075723.1,GQ902063.1, EF623987.1,JN381871.1,JF706283.1,JN381865.1,EF107 523.1,AY849939.1,JN381853.1,JN381854.1,U47032.1,JF 706276.1,JN381858.1,JF706272.1,JN381856.1,JN381857 .1,JN381855.1,JF706273.1,JN381859.1,JN381860.1,JN3 81861.1,JN381863.1,JN381862.1,JN381864.1,JN381867. 1,JN381866.1,L48961.1,L78128.1,JN381868.1,EF571853 .1,HE861351.1,JN711459.1,JN711458.1,JF706284.1,FJ1 85037.1,FJ185036.1,JF706285.1,JX072965.1,JX050179.1, JX131374.1,AF080251.1,JN644310.1| mosquito

mosquito
NC_001563.2,KC601756.1,JQ928175.1,JQ928174.1,AF 404757.1,AF404756.1,AF404755.1,AF404754.1,AF4047 53.1,AY646354.1,GQ379161.1,GQ379160.1,GQ379159. 1,GQ379158.1,GQ379157.1,GQ379156.1,GU011992.2, AY842931.3,FJ527738.1,DQ377180.1,DQ377179.1,DQ 377178.1,KF647253.1,KF647252.1,KF647251.1,KF6472 50.1,KF647249.1,KF647248.1,KF588365.1,KF179640.1, KF179639.1,KF234080.1,JN393308.1,JF957186.1,JF957 185.1,JF957184.1,JF957183.1,JF957182.1,JF957181.1,JF 957180.1,JF957179.1,JF957178.1,JF957177.1,JF957176.1 ,JF957175.1,JF957174.1,JF957173.1,JF957172.1,JF95717 1.1,JF957170.1,JF957169.1,JF957168.1,JF957167.1,JF95 7166.1,JF957165.1,JF957164.1,JF957163.1,JF957162.1,J F957161.1,JF719069.1,JF719068.1,JF719067.1,JF719066 .1,JF719065.1,FJ411043.1,AY660002.1,AF206518.2,AF2 60968.1,AF260967.1,AY765264.1,DQ176636.2,DQ1766 37.1,KF704158.1,KF704153.1,KF704147.1,KC954092.1, KC711059.1,KC711057.1,KC736502.1,KC736501.1,KC 736500.1,KC736499.1,KC736498.1,KC736497.1,KC736 496.1,KC736495.1,KC736494.1,KC736493.1,KC736492. 1,KC736491.1,KC736490.1,KC736489.1,KC736488.1,K C736487.1,KC736486.1,JQ700442.1,JQ700441.1,JQ700 440.1,JQ700439.1,JQ700438.1,JQ700437.1,HM147824.1 HM147823.1,HM147822.1,JX123031.1,JX123030.1,JX5 56213.1,HM488124.1,HM488123.1,HM488122.1,HM4 88176.1,HM488175.1,HM488174.1,HM488173.1,HM4 88172.1,HM488171.1,HM488170.1,HM488169.1,HM4 88168.1,HM488167.1,HM488166.1,HM488165.1,HM4 88164.1,HM488163.1,HM488162.1,HM488161.1,HM4 88160.1,HM488159.1,HM488158.1,HM488157.1,HM4 88156.1,HM756659.1,HM756658.1,HM756657.1,HM7 56656.1,HM756654.1,HM756653.1,HM756652.1,HM7 56651.1,HM756650.1,HM756649.1,HM756648.1,HM4 88236.1,HM488235.1,HM488234.1,HM488233.1,HM4 88232.1,HM488231.1,HM488230.1,HM488229.1,HM4 88228.1,HM488227.1,HM488226.1,HM488225.1,HM4 88224.1,HM488223.1,JN858070.1 


\section{Continued}

Powassan virus

tick

Tick-borne encephalitis virus

Dengue virus
NC_003687.1,HQ231415.1

2

NC_001672.1,AY169390.3,KF151173.1,FJ968751.1,HM 535611.1,HM535610.1,HQ201303.1,GU121642.1,GQ22 8395.1,FJ997899.1,FJ906622.1,EU816455.2,FJ402886.1,F J402885.1,EU816454.1,EU816453.1,KC835597.1,KC835 596.1,KC835595.1,DQ401140.3,KC414090.1,JF819648.2 ,HQ901367.1,HQ901366.1,HM859895.1,HM859894.1,E U816452.1,EU816451.1,EU816450.1,GQ266392.1,AF06 9066.1,FJ572210.1,JX534167.1,AB753012.1,JQ650523.1, JQ650522.1,JF316708.1,JF316707.1,KJ000002.1,KF9510 37.1,EF469662.1,EF469661.1

DENV1:AF311957,AF311958,AF513110,EU482497, EU482500-EU482502,EU482509,EU482511,EU482512, EU482515,EU482516,EU482521,EU482525,EU482526,E U482533-EU482535,EU482538,EU482539,EU482567,E U482706,EU482800,EU482802,EU482803,EU482822,E U482823,EU596501,EU660390,EU660391,EU687247,E U848545,FJ024423,FJ024440,FJ024441,FJ024442,FJ0244 46,FJ024448,FJ024472,FJ024480,FJ024481,FJ205873,FJ2 05874,FJ410290,FJ432720,FJ461307,FJ461308,FJ461310, FJ461330,FJ461335,FJ461336,FJ461341,FJ639669,FJ6396 70,FJ639671,FJ639673,-FJ639678,FJ639680-FJ639684,FJ 639686,FJ639688,FJ639692,FJ639796,FJ639797,FJ63980 2,FJ639812-FJ639814,FJ639824,FJ687432,FJ687433,FJ74 4701,FJ744702,FJ810415,FJ810419,FJ850068,FJ850069,F J898391,FJ898423,FJ898424,FJ898430,FJ898431,FJ89843 3,FJ898437,FJ898448,FN429881-FN429883,FN429887,F N429889,FN429890,GQ199771,GQ199772,GQ199791,G Q199793,GQ199794,GQ199817-GQ199819,GQ199827GQ199829,GQ199831-GQ199833,GQ199836-GQ19983 8,GQ199852-GQ199854,GQ199856-GQ199859, GQ199873, GQ199875, J461323, J639823 DENV2:NC_001474,AB122020-AB122024,AF489932,A Y702034,AY702040,AY744147,AY858035,AY858036,D Q181797,DQ181798, DQ181803, DQ181804, DQ181806,EF051521,EF457904,EU056810,EU056811,E U056812,EU179857-EU179859,EU359009,EU482608,E U660415,EU677145,EU687212,EU687213, EU687217, EU687220, EU687225, EU687232,

EU687241-EU687243,EU687246,EU726767,EU726775, EU781135,FJ024475,FJ024477,FJ182012,FJ226066,FJ390 389,FJ410259,FJ410288,FJ432726,FJ461311,FJ639700,FJ 639705,FJ639706,FJ639711,FJ639717,FJ639718,FJ63978 3,FJ639822,FJ810412, FJ850067,FJ850072,FJ850074, FJ850076, FJ850078, FJ850082,FJ850085,FJ850088, FJ850108, FJ850112,

FJ906962,FM210202,FM210204,FM210206-FM210213, FM210216-FM2102123,FM210231-FM210234, FM210236-FM210244, FN429891, FN429892, FN429895,GQ199869,GQ199874,GQ199890, GQ199892,GQ199893,GQ199895-GQ199898, GQ199901,GQ252676,GQ252677,M20558,M29095, MD1515

DENV3:NC_001475,AY099337,AY766104,AY770511,D Q863638, EU529699, EU660420, EU854292, FJ182013,FJ182041,FJ898441-FJ898445, FJ898455-FJ898459,FJ898462-FJ898464, FJ898468, 


\section{Continued}

Orthobunyavirus

Bunyaviridae

Toscana virus
FJ898471,FJ898472,FJ898474,

FN429897-FN429900,FN429904,FN429907,

FN429909,FN429911,FN429913,GQ199889,GQ199891, GQ252674, GQ252678, M93130

DENV4:AY947539,EU854295-EU854297,EU854299-E

U854301,FJ024424,FJ024476,FJ182016,

FJ182017,FJ882590-FJ882592, FJ882595-FJ882601,

FN429919-FN429922,FN429924-FN429926,GQ199876GQ199882,GQ199884,GQ252675,MY0327498, MY95328

\section{California} encephalitis virus

mosquito

La Crosse virus

mosquito

Rift valley fever virus

Phlebovirus
U12800.1,AF123483.1

NC_004110.1,NC_004109.1,NC_004108.1,GU591168.1, GU591166.1,GU591165.1,GU591167.1,GU591164.1,GU 591169.1,K00610.1,EF485038.1,EF485037.1,EF485036.1, EF485035.1,EF485034.1,EF485033.1,EF485032.1,EF485 031.1,EF485030.1

NC_014396.1,JF784387.1,JF311385.1,JF311384.1,JF3113 83.1,JF311382.1,JF311381.1,JF311380.1,JF311379.1,JF31 1378.1,JF311377.1,DQ380222.1,DQ380221.1,DQ380220 .1,DQ380219.1,DQ380218.1,DQ380217.1,DQ380216.1, DQ380215.1,DQ380214.1,DQ380212.1,DQ380211.1,DQ 380210.1,DQ380209.1,DQ380207.1,DQ380206.1,DQ380 205.1,DQ380204.1,DQ380203.1,DQ380200.1,DQ380198 .1,DQ380197.1,DQ380196.1,DQ380195.1,DQ380194.1, DQ380191.1,DQ380190.1,DQ380189.1,DQ380188.1,DQ 380187.1,DQ380186.1,DQ380185.1,DQ380184.1,DQ380 183.1,HE687306.1,HE687303.1

NC_006320.1,JX867535.1,EU003177.1,EU003180.1,EU0 03179.1,EU003178.1,EU003176.1,EU003175.1,EU00317 4.1,EU003173.1

Table S2. Viral RNA standards prepared via in vitro transcription.

\begin{tabular}{|c|c|c|c|c|c|}
\hline virus & source & $\begin{array}{l}\text { GenBank accession number of } \\
\text { the referenced sequence }\end{array}$ & Length (nt) & $\begin{array}{l}\text { Concentration } \\
(\mathrm{ng} / \mathrm{mL})\end{array}$ & $\begin{array}{c}\text { Copy } \\
\text { number }(\text { copies } / \mu \mathrm{L})\end{array}$ \\
\hline Eastern equine encephalitis virus & Chemical synthesis & NC_003899.1 & 750 & 867 & $2.0468 \mathrm{E} 12$ \\
\hline Western equine encephalitis virus & Chemical synthesis & NC_003908.1 & 759 & 904 & $2.1088 \mathrm{E} 12$ \\
\hline Venezuelan equine encephalitis virus & Chemical synthesis & NC_001449.1 & 935 & 1020 & $1.9316 \mathrm{E} 12$ \\
\hline Chikungunya virus & Virus isolate & NC_004162.2 & 968 & 820 & $1.4999 \mathrm{E} 12$ \\
\hline Japanese encephalitis virus & Virus isolate & NC_001437.1 & 967 & 856 & $1.5673 \mathrm{E} 12$ \\
\hline Saint Louis encephalitis virus & Chemical synthesis & NC_007580.2 & 1011 & 896 & $1.5692 \mathrm{E} 12$ \\
\hline Murray Valley encephalitis virus & Chemical synthesis & NC_000943.1 & 714 & 351 & $8.7042 \mathrm{E} 11$ \\
\hline West Nile virus & Virus isolate & NC_001563.2 & 1224 & 1388 & $2.0078 \mathrm{E} 12$ \\
\hline Powassan virus & Chemical synthesis & NC_003687.1 & 1476 & 712 & $8.541 \mathrm{E} 11$ \\
\hline Tick-borne encephalitis virus & Virus isolate & NC_001672.1 & 1127 & 893 & $1.403 \mathrm{E} 12$ \\
\hline Dengue virus & Virus isolate & NC_001474.1 & 730 & 859 & $2.0835 \mathrm{E} 12$ \\
\hline California encephalitis virus & Chemical synthesis & U12800.1 & 1365 & 315 & $4.086 \mathrm{E} 11$ \\
\hline La Crosse virus & Virus isolate & NC_004109.1 & 1048 & 822 & $1.3888 \mathrm{E} 12$ \\
\hline Rift valley fever virus & Virus isolate & NC_014396.1 & 839 & 925 & $1.9521 \mathrm{E} 12$ \\
\hline Toscana virus & Chemical synthesis & NC_006320.1 & 1237 & 416 & $5.9544 \mathrm{E} 11$ \\
\hline
\end{tabular}


Table S3. Reproducibility analysis of multiplex one-step real-time RT-PCR assays.

\begin{tabular}{|c|c|c|c|c|c|c|}
\hline \multirow{2}{*}{ Assays } & \multirow{2}{*}{$\begin{array}{c}\text { RNA } \\
\text { transcripts }\end{array}$} & \multirow{2}{*}{$\begin{array}{l}\text { RNA transcripts } \\
\text { concentration }\end{array}$} & \multirow{2}{*}{$\begin{array}{c}\text { Mean Ct } \\
\text { value }\end{array}$} & \multicolumn{2}{|c|}{ Intra-assay Inter-assay } & \multirow{2}{*}{ linear range } \\
\hline & & & & CV (\%) & CV (\%) & \\
\hline \multirow{10}{*}{ Group A } & \multirow{5}{*}{ EEEV } & $10^{7}$ copies $/ \mu \mathrm{L}$ & 18.13 & 1.96 & 3.41 & \multirow{5}{*}{$\begin{array}{c}\mathrm{Y}=3.46 \mathrm{x}+46.25 \\
\mathrm{R} 2=0.996\end{array}$} \\
\hline & & $10^{6}$ copies $/ \mu \mathrm{L}$ & 22.06 & 2.17 & 2.01 & \\
\hline & & $10^{5}$ copies $/ \mu \mathrm{L}$ & 25.22 & 1.22 & 1.59 & \\
\hline & & $10^{4}$ copies $/ \mu \mathrm{L}$ & 29.31 & 1.05 & 0.51 & \\
\hline & & $10^{3}$ copies $/ \mu \mathrm{L}$ & 33.17 & 1.29 & 0.3 & \\
\hline & \multirow{5}{*}{ WEEV } & $10^{7}$ copies $/ \mu \mathrm{L}$ & 20.02 & 4.81 & 4.68 & \multirow{5}{*}{$\begin{array}{c}\mathrm{Y}=3.68 \mathrm{x}+47.65 \\
\mathrm{R} 2=0.988\end{array}$} \\
\hline & & $10^{6}$ copies $/ \mu \mathrm{L}$ & 22.96 & 3.28 & 0.56 & \\
\hline & & $10^{5}$ copies $/ \mu \mathrm{L}$ & 26.14 & 1.47 & 0.82 & \\
\hline & & $10^{4}$ copies $/ \mu \mathrm{L}$ & 30.11 & 1.3 & 0.4 & \\
\hline & & $10^{3}$ copies $/ \mu \mathrm{L}$ & 34.15 & 0.95 & 0.71 & \\
\hline \multirow{10}{*}{ Group B } & \multirow{5}{*}{ VEEV } & $10^{7}$ copies $/ \mu \mathrm{L}$ & 17.51 & 4.46 & 1.52 & \multirow{5}{*}{$\begin{array}{c}Y=3.66 x+47.2 \\
R 2=0.998\end{array}$} \\
\hline & & $10^{6}$ copies $/ \mu \mathrm{L}$ & 21.04 & 3.3 & 0.21 & \\
\hline & & $10^{5}$ copies $/ \mu \mathrm{L}$ & 24.16 & 2.77 & 0.58 & \\
\hline & & $10^{4}$ copies $/ \mu \mathrm{L}$ & 27.20 & 0.69 & 0.44 & \\
\hline & & $10^{3}$ copies $/ \mu \mathrm{L}$ & 30.43 & 1.7 & 0.59 & \\
\hline & \multirow{5}{*}{ CHIKV } & $10^{7}$ copies $/ \mu \mathrm{L}$ & 19.65 & 0.59 & 0.59 & \multirow{5}{*}{$\begin{array}{c}\mathrm{Y}=3.58 \mathrm{x}+47.49 \\
\mathrm{R} 2=0.999\end{array}$} \\
\hline & & $10^{6}$ copies $/ \mu \mathrm{L}$ & 22.14 & 2.74 & 2.74 & \\
\hline & & $10^{5}$ copies $/ \mu \mathrm{L}$ & 25.63 & 0.73 & 0.73 & \\
\hline & & $10^{4}$ copies $/ \mu \mathrm{L}$ & 29.07 & 0.37 & 0.37 & \\
\hline & & $10^{3}$ copies $/ \mu \mathrm{L}$ & 33.12 & 0.14 & 0.14 & \\
\hline \multirow{10}{*}{ Group C } & \multirow{5}{*}{ MVEV } & $10^{7}$ copies $/ \mu \mathrm{L}$ & 14.82 & 2.87 & 1.27 & \multirow{5}{*}{$\begin{array}{c}\mathrm{Y}=3.53 \mathrm{x}+46.31 \\
\mathrm{R} 2=0.998\end{array}$} \\
\hline & & $10^{6}$ copies $/ \mu \mathrm{L}$ & 18.31 & 1.39 & 1.64 & \\
\hline & & $10^{5}$ copies $/ \mu \mathrm{L}$ & 23.85 & 0.73 & 1.72 & \\
\hline & & $10^{4}$ copies $/ \mu \mathrm{L}$ & 28.02 & 0.79 & 1.32 & \\
\hline & & $10^{3}$ copies $/ \mu \mathrm{L}$ & 32.97 & 1.17 & 0.68 & \\
\hline & \multirow{5}{*}{ SLEV } & $10^{7}$ copies $/ \mu \mathrm{L}$ & 14.57 & 2.82 & 0.98 & \multirow{5}{*}{$\begin{array}{c}Y=3.56 x+46.69 \\
R 2=0.997\end{array}$} \\
\hline & & $10^{6}$ copies $/ \mu \mathrm{L}$ & 18.61 & 3.08 & 4.06 & \\
\hline & & $10^{5}$ copies $/ \mu \mathrm{L}$ & 24.03 & 1.97 & 0.9 & \\
\hline & & $10^{4}$ copies $/ \mu \mathrm{L}$ & 28.09 & 1.03 & 0.68 & \\
\hline & & $10^{3}$ copies $/ \mu \mathrm{L}$ & 33.11 & 2.15 & 0.81 & \\
\hline \multirow{3}{*}{ Group D } & \multirow{3}{*}{ WNV } & $10^{7}$ copies $/ \mu \mathrm{L}$ & 14.61 & 2.2 & 3.79 & \multirow{3}{*}{$\begin{array}{c}\mathrm{Y}=3.54 \mathrm{x}+47.26 \\
\mathrm{R} 2=0.997\end{array}$} \\
\hline & & $10^{6}$ copies $/ \mu \mathrm{L}$ & 19.58 & 1.16 & 0.37 & \\
\hline & & $10^{5}$ copies $/ \mu \mathrm{L}$ & 24.64 & 0.14 & 0.21 & \\
\hline
\end{tabular}




\section{Continued}

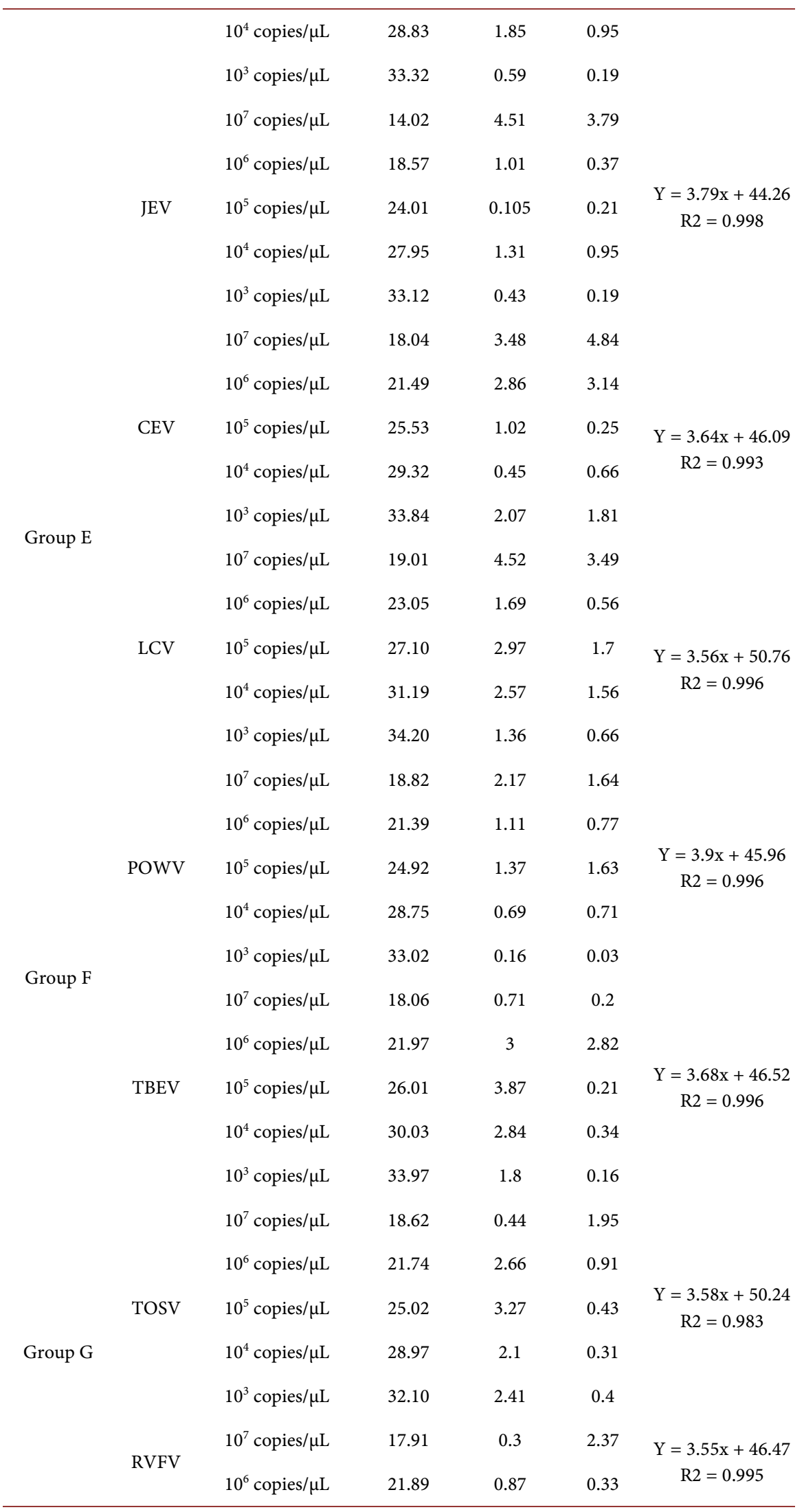




\begin{tabular}{|c|c|c|c|c|c|c|}
\hline \multicolumn{7}{|c|}{ Continued } \\
\hline & & $10^{5}$ copies $/ \mu \mathrm{L}$ & 25.92 & 1.48 & 0.93 & \multirow{8}{*}{$\begin{array}{c}\mathrm{Y}=3.65 \mathrm{x}+50.15 \\
\mathrm{R} 2=0.992\end{array}$} \\
\hline & & $10^{4}$ copies $/ \mu \mathrm{L}$ & 30.02 & 1.04 & 0.09 & \\
\hline \multirow{6}{*}{ Group H } & \multirow{6}{*}{ DENV } & $10^{3}$ copies $/ \mu \mathrm{L}$ & 33.89 & 2.11 & 0.27 & \\
\hline & & $10^{7}$ copies $/ \mu \mathrm{L}$ & 18.94 & 4.65 & 3.66 & \\
\hline & & $10^{6}$ copies $/ \mu \mathrm{L}$ & 22.87 & 1.91 & 0.26 & \\
\hline & & $10^{5}$ copies $/ \mu \mathrm{L}$ & 26.10 & 1.81 & 0.64 & \\
\hline & & $10^{4}$ copies $/ \mu \mathrm{L}$ & 29.83 & 1.07 & 0.1 & \\
\hline & & $10^{3}$ copies $/ \mu \mathrm{L}$ & 33.17 & 1.13 & 0.25 & \\
\hline
\end{tabular}

$\mathrm{CV}$, coefficient of variation. Intra-assays were determined from two replicates within each dilution. Inter-assays were determined from three independent assays performed on different days.

\section{Abbreviations}

CNS: Central Nervous System;

EEEV: Eastern Equine Encephalitis Virus;

WEEV: Western Equine Virus;

VEEV: Venequilan Equine Encephalitis Virus;

JEV: Japanese Encephalitis Virus;

SLEV: St. Louis Encephalitis Virus;

MVEV: Murray Valley Encephalitis Virus;

WNV: West Nile Encephalitis Virus;

POWV: Powassan Virus;

CEV: Californiaencephalitis Virus;

LCV: La Crosse Virus;

TBEV: Tick-Borne Encephalitis Virus;

RVFV: Rift valley Fever Virus;

TOSV: Toscana Virus;

DENV: Dengue Virus;

CHIKV: Chikungunya Virus;

LOD: Limit of Detection;

IC: Internal Control. 